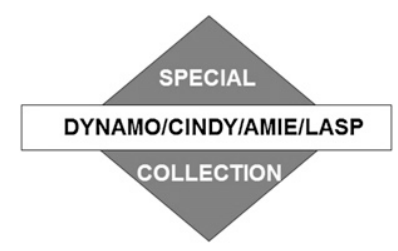

\title{
Use of an End-to-End-Simulator to Analyze CYGNSS
}

\author{
KACIE E. HoOver AND JOHn R. MeciKAlsKi \\ Atmospheric Science Department, University of Alabama in Huntsville, Huntsville, Alabama \\ TIMOTHY J. LANG \\ NASA Marshall Space Flight Center, Huntsville, Alabama \\ XUANLI LI \\ Earth System Science Center, University of Alabama in Huntsville, Huntsville, Alabama \\ TYler J. CASTILlO \\ Department of Atmospheric Science, University of Alabama in Huntsville, Huntsville, Alabama \\ THEMIS CHRONIS \\ Earth System Science Center, University of Alabama in Huntsville, Huntsville, Alabama
}

(Manuscript received 1 March 2017, in final form 3 October 2017)

\begin{abstract}
Tropical convection during the onset of two Madden-Julian oscillation (MJO) events, in October and December of 2011, was simulated using the Weather Research and Forecasting (WRF) Model. Observations from the Dynamics of the MJO (DYNAMO) field campaign were assimilated into the WRF Model for an improved simulation of the mesoscale features of tropical convection. The WRF simulations with the assimilation of DYNAMO data produced realistic representations of mesoscale convection related to westerly wind bursts (WWBs) as well as downdraft-induced gust fronts. An end-to-end simulator (E2ES) for the Cyclone Global Navigation Satellite System (CYGNSS) mission was then applied to the WRF dataset, producing simulated CYGNSS near-surface wind speed data. The results indicated that CYGNSS could detect mesoscale wind features such as WWBs and gust fronts even in the presence of simulated heavy precipitation. This study has two primary conclusions as a consequence: 1) satellite simulators could be used to examine a mission's capabilities for accomplishing secondary tasks and 2) CYGNSS likely will provide benefits to future tropical oceanic field campaigns that should be considered during their planning processes.
\end{abstract}

\section{Introduction}

The world's oceans are vast data-void regions. To combat the lack of high-resolution ocean surface wind data, the Cyclone Global Navigation Satellite System (CYGNSS) mission was launched to retrieve wind speeds (Ruf et al. 2016). The main objective for CYGNSS, which is composed of eight bistatic microscatterometers, is to accurately and quickly retrieve rapidly changing wind

Corresponding author: John R. Mecikalski, john.mecikalski@ nsstc.uah.edu speeds within precipitating regions of tropical cyclones, in order to improve the forecasting operations. The CYGNSS scatterometers are unique in that they collect data in the $\mathrm{L}$ band to retrieve wind speed information using reflected signals from the U.S. global positioning system (GPS) across the tropics (between $\sim 35^{\circ} \mathrm{N}$ and $\sim 35^{\circ} \mathrm{S}$ ). CYGNSS operates differently from other scatterometers [e.g., QuikSCAT, Advanced Scatterometer (ASCAT), and OceanSat-2 Scatterometer (OSCAT)] in that clear-sky to light-precipitation conditions are not required in order to obtain accurate high-spatiotemporalresolution ocean surface wind speed data. Specifically, 
CYGNSS will be able to retrieve surface wind speed information in regions of moderate to heavy precipitation, unlike the scatterometer instruments listed above. The CYGNSS instrument is also expected to be useful for measuring a variety of other weather phenomena that occur in the tropics, in particular the deep convection associated with the Madden-Julian oscillation (MJO; Madden and Julian 1971, 1972).

The CYGNSS constellation was launched on 15 December 2016. Before that, an end-to-end-simulator (E2ES; O'Brien 2014; O'Brien et al. 2015) was used to simulate the data that CYGNSS provides. Simulated data are useful in a variety of science studies, including direct analysis of spatial and temporal wind fields, as these are expected from CYGNSS, and for use in preliminary process studies, especially wind-evaporation relationships within and near precipitating convective storms. As a step toward generating a simulated CYGNSS wind speed dataset, this study performed Weather Research and Forecasting (WRF; Skamarock et al. 2008) Model simulations for two different MJO events with the assimilation of observations collected during the 2011-12 Dynamics of the MJO (DYNAMO) field campaign (Zhang et al. 2013).

The purpose of this study was twofold: 1) To demonstrate how satellite simulators can be used to examine a mission's capabilities for accomplishing secondary tasks (in the case of CYGNSS, characterizing tropical convection and the MJO) and 2) to examine how CYGNSS surface wind observations can add value to future tropical oceanic field campaigns. Hence, a major focus of this paper is to demonstrate the use of the E2ES to simulate CYGNSS data, specifically describing how input data for the simulator were prepared, ways that the simulator was employed, and how the resulting simulated CYGNSS winds were evaluated from a scientific perspective. Given the use of DYNAMO campaign observations, the study sought to assess the ability of CYGNSS to characterize mesoscale convective variability associated with tropical convection during $\mathrm{MJO}$ events, namely, small-scale $[O(10) \mathrm{km}]$ wind and associated surface flux variability. Such convection is commonly organized into clusters that are associated with westerly wind bursts (WWBs) in the Indian Ocean, and individual mesoscale convective systems (MCSs) within these clusters often produce locally enhanced near-surface wind speeds associated with downdraftinduced gust fronts. Although we focus on simulated data, the goal is to provide an outline of the processing steps that may be followed by others in evaluating output from simulators similar to the E2ES, in particular for understanding how a mission may be applicable to tasks other than its primary one.

\section{Background}

\section{a. The $\mathrm{MJO}$}

The MJO is a large-scale $(\sim 1000 \mathrm{~km})$ atmospheric circulation defined by eastward propagation of enhanced convection across the equatorial tropical ocean (Madden and Julian 1971, 1972) at an average speed of $5 \mathrm{~m} \mathrm{~s}^{-1}$ (Weickmann et al. 1985; Knutson et al. 1986). It has a planetary mode of 30-90 days and influences both daily weather and climatological patterns, which makes it the dominant intraseasonal variability across the tropics (Zhang 2005). The convective signal of the oscillation is associated with enhanced evaporation, cloudiness, and rainfall. The MJO typically initiates and tracks from a source region in the Indian Ocean, and decays as it reaches the western and central Pacific Ocean. It has been observed to influence tropical cyclones in the Indian, Pacific, and Atlantic Oceans (Kim et al. 2008; Klotzbach 2010); monsoons (Goswami 2012; Wheeler and McBride 2012; Mo et al. 2012); the rainfall distribution across a large part of the Eastern Hemisphere (Zhang 2013); and the El Niño-Southern Oscillation (Hendon et al. 2007). Barrett and Leslie (2009) showed a significant MJO signal in tropical cyclone activity across most of the Western Hemisphere.

Seasonally, the MJO signal peaks during boreal winter (December-February), which coincides with the Australian summer monsoon (Hendon and Liebmann 1990), and spring (March-May; Woolnough et al. 2000; Zhang 2005), and has a secondary peak during boreal summer (June-August) that is related to the Asian summer monsoon (Lawrence and Webster 2002). The studies by Wheeler and Hendon (2004) and LaFleur et al. (2015) documented the seasonality of the MJO using the real-time multivariate MJO (RMM) index, finding similar results to these prior studies.

Madden and Julian noted in their early studies that the MJO is likely associated with a feedback mechanism. Such a mechanism could be defined by the wind-induced surface heat exchange (WISHE; Emanuel 1987, 1993 , 1994; Sobel et al. 2010; Fuchs and Raymond 2017) or evaporation-wind feedback (EWF; Neelin et al. 1987) theories, which attempt to explain the eastward propagation and growth of the enhanced deep convection as a function of the associated wind fields within the MJO. It is hypothesized that a variant of the WISHE mechanism helps drive the organization and evolution of tropical MCSs in a manner that is independent of geographic location (see Solodoch et al. 2011). That is, wind-driven turbulent fluxes of heat and water vapor from the ocean surface supply moisture to support convection. This convection in turn produces precipitation-laden storm outflows that increase local winds, which then provide 
additional water vapor in a positive feedback loop. This moistening is hypothesized to occur over a significant depth in the troposphere. Although WISHE-like processes do not completely explain, for example, MJO onset and propagation (Sobel and Maloney 2013), they are likely relevant for MCSs.

The recent modeling results of Riley-Dellaripa et al. (2016) showed a time-varying degree of spatial offset between the precipitation maximum for a composite tropical convective system during the MJO onset and the wind-driven latent heat flux maximum. They found that only at precipitation system maturity do these maxima coincide spatially, optimizing the support of latent heat fluxes for the existing precipitation. However, during the genesis (decay) stage, surface fluxes lag (lead) the position of the precipitation maximum, suggesting that a fine balance between gust-front dynamics, precipitation system propagation, and boundary layer saturation is needed for maximum convective support. Although large-scale moisture convergence is a significant control for precipitation, surface fluxes are strongly influenced by the enhanced winds in convective cold pools (Skyllingstad and de Szoeke 2015). The spatiotemporal behavior of these fluxes in turn is hypothesized to control the evolution and organizational mode of MCSs, via mesoscale modifications to moisture supply and instability (Markowski and Richardson 2010) and, subsequently, the location of increased cloudiness and precipitation in turn influences large-scale convergence. Given that CYGNSS can observe subdiurnal winds even in the presence of heavy rainfall, it is an excellent platform for testing these hypotheses.

\section{b. MJO events within the DYNAMO field campaign}

The DYNAMO campaign was conducted from October 2011 to March 2012. DYNAMO focused on the early stages of the MJO with instruments set up across the Indian Ocean near the Maldives, as well as in the western Pacific Ocean (Moum et al. 2014). DYNAMO intensively observed three MJO events in 2011 that are named here for the month in which each occurred: October, November, and December. Observations were able to continue on Manus Island in the western Pacific until the end of the project on 31 March 2012 (Yoneyama et al. 2013). A main driving hypothesis of DYNAMO that aligns with this study is that low-level winds drive mixing and entrainment, both of which are essential to MJO initiation over the Indian Ocean through surface flux feedback (Yoneyama et al. 2013).

The DYNAMO field experiment was set up across a large area in order to sufficiently capture "the full initiation cycle of at least one MJO event" (Yoneyama et al. 2013). The experimental design included two quadrilateral arrays for soundings that had sites across the Maldives, in Sri Lanka, and on two research vessels $(\mathrm{R} / \mathrm{V})$. Observations were made at sites that included Male and the Addu Atoll, the Maldives, Diego Garcia Island, Columbo, Sri Lanka, R/V Roger Revelle (situated at $0^{\circ}, 80.5^{\circ} \mathrm{E}$ ), and R/V Mirai (situated at $8^{\circ} \mathrm{S}$, $\left.80.5^{\circ} \mathrm{E}\right)$. Two radars and the Atmospheric Radiation Measurement Mobile Facility (AMF2) were set up on the Addu Atoll. Manus Island in the western Pacific had a similar set up to that on the Addu Atoll in order to capture the same MJO event at both its initiation stage and mature stage. Data were collected via various instruments, including soundings, radar, buoys, and instruments aboard research vessels and aircraft.

At the beginning of the campaign, there was an ongoing moderate phase of the La Niña that reached its peak from November 2011 to February 2012, with Niño-3.4 sea surface temperature (SST) anomalies of roughly $-1{ }^{\circ} \mathrm{C}$. There was a positive Indian Ocean dipole (IOD) signal during October that dissipated by December. The warmest SSTs in the Indian Ocean were located to the north of the equator and were roughly $29^{\circ}-30^{\circ} \mathrm{C}$ (Gottschalck et al. 2013). The upward branch of the Walker circulation was located over the eastern Indian Ocean $\left(60^{\circ}-150^{\circ} \mathrm{E}\right)$ and the descending portion over the central and eastern Pacific Ocean. During the October event, there were very little effects from the austral summer monsoon circulation along with a persistent zonally flat thermocline for much of October and November. The ITCZ was positioned south of the equator over the Indian Ocean, as is typical for boreal winter, and strong equatorial westerlies were set up during December and into January (Gottschalck et al. 2013). For a more in-depth overview of the entire DYNAMO project, the reader is directed to Yoneyama et al. (2013) for the setup of the project, to Gottschalck et al. (2013) for the large-scale conditions, and to de Szoeke et al. (2015) for air-sea interactions.

The first three MJO events of DYNAMO are interesting because they can each be labeled as highfrequency, or short interval, MJO events that each had an approximately 30-day oscillation. The RMM index for these events can be seen in Fig. 1, which was used to classify a given MJO's intensity. From Fig. 1, the November 2011 MJO event was the strongest of the three, while the December case was classified as a "weak" MJO event. For the purposes of the CYGNSS E2ES evaluation, this study selected convective days during the October and the December MJO events in order to determine the usefulness of CYGNSS for observing mesoscale features of tropical convective storms within MJO events. For the October 2011 MJO event, there was an evident change in convection type between 
(a) October 2011

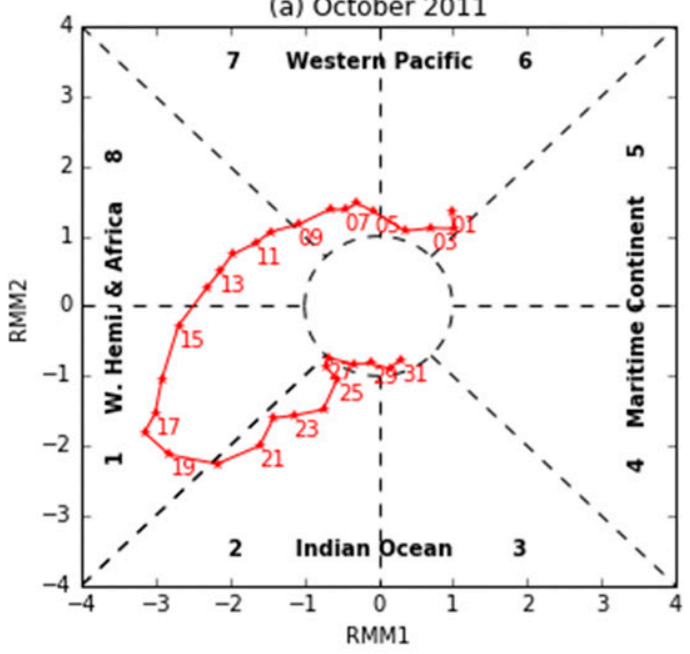

(b) November 2011

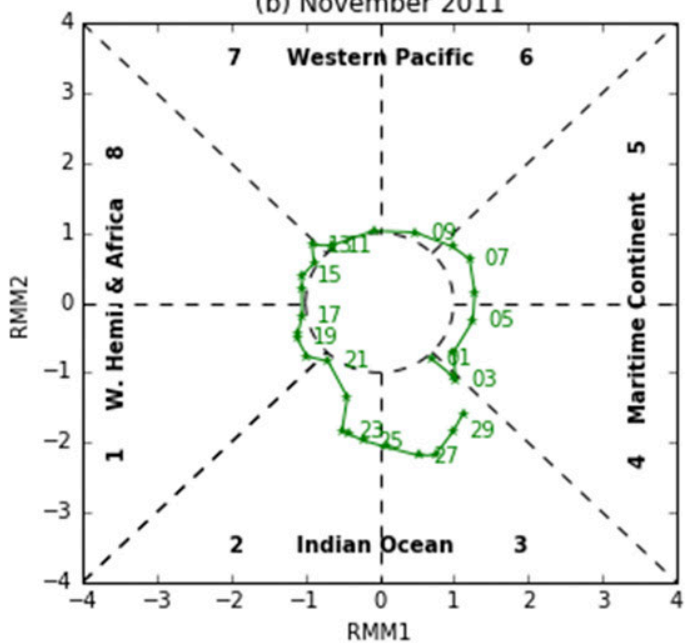

(c) December 2011

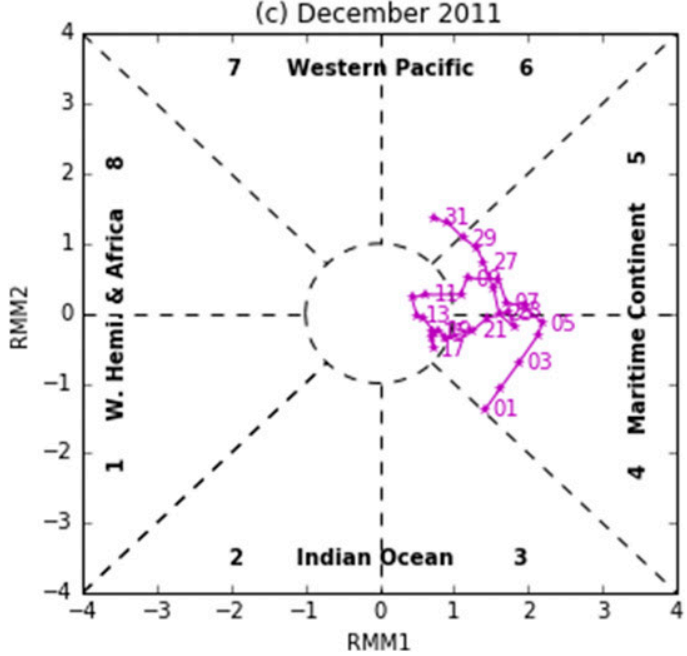

FIG. 1. RMM indices for (a) October, (b) November, and (c) December 2011. Data and plot style are from Gottschalk et al. (2013). Points outside the circle indicate a significant MJO event, while phase triangles indicate its primary location.
1-15 and 16-30 October. Isolated convective cells dominated the first half of the month, while deeper convection was present during the second half (Zuluaga and Houze 2013; Powell and Houze 2013; Xu and Rutledge 2015). The MJO signal (Fig. 1a) was already peaking in strength as it moved over the Indian Ocean in the middle of October from phase 1 into phase 2. The MJO weakened just before reaching phase 3, at the end of the month. Much of the precipitation was located over the eastern equatorial Indian Ocean, with the heaviest precipitation being located toward the southwestern portion of the Indian Ocean. The December MJO proved to be a complex case. The RMM index phase diagram shows that this weak event became definable on 19 December 2011 and died out by 4 January 2012 as it fell into phases 4-6 (Fig. 1c). The RMM index of this event does not have a clear counterclockwise motion around the center of the index. Ling et al. (2014) has set 14 December 2011 as the initiation date of this MJO event and claimed the December case as "unconventional and controversial" and "barely existed" from the observed RMM index. Gottschalck et al. (2013) argued that although less coherent, robust MJO activity was found between mid-December 2011 and January 2012, the velocity potential at $200 \mathrm{hPa}$ did exhibit MJO-like dynamical properties as a subseasonal event.

\section{c. CYGNSS}

As noted above, the CYGNSS microsatellite constellation will help combat the lack of wind data in otherwise data-void regions across the tropical oceans, especially in and near regions of precipitation that have otherwise been very challenging to observe with remote sensing. Convection across the tropics is highly dependent on the complex and dynamic air-sea interactions at the low levels and throughout the troposphere (Ruf et al. 2013b). Therefore, one of the primary goals of the CYGNSS mission is to improve tropical cyclone genesis and intensity forecasts, but the data can also be used to improve MJO forecasting.

By studying how CYGNSS would have observed MJO onsets during DYNAMO, the present study demonstrates how CYGNSS datasets will be relevant to future field campaigns that are focused (at least in part) on tropical oceanic convection, including the forthcoming Propagation of Intraseasonal Tropical Oscillations (PISTON), the Years of the Maritime Continent (YMC), and the Cloud and Aerosol Monsoonal ProcessesPhilippines Experiment (CAMP $\left.{ }^{2} \mathrm{Ex}\right)$.

The geometry associated with the satellite setup is based on the Global Navigation Satellite System (GNSS) approach, which is already utilized by the U.S. 
global positioning system (GPS) and the Russian Globalnaya Navigatsionnaya Sputnikovaya Sistema (GLONASS; Ruf et al. 2013b). Each microsatellite receives both direct and reflected signals from GPS satellites. The direct signals locate observation positions, while the quasi-linear, forward-scattered signals provide detailed information of ocean surface roughness from which wind speed can be derived (Ruf et al. 2013a). Combining the information received by each satellite goes into creating the delay-Doppler map (DDM), which shows the spatial distribution of scattering from the ocean surface (Ruf et al. 2013b). Higher wind speeds will lead to more abundant scattered signals from more waves across the ocean surface, while a wind speed of zero would resemble a pinpoint off the ocean's surface, as the signal would not be affected by diffuse scattering. This GPS signal-receiving method has already been demonstrated by the U.K. Disaster Monitoring Constellation-1 (UK-DMC-1; deployed in 2003) and the Technology Demonstration Satellite-1 (TechDemoSat-1; Foti et al. 2015) to provide valuable data (Ruf et al. 2013b).

\section{Data and methodology}

\section{a. DYNAMO observations}

A variety of instruments were deployed with high temporal and spatial resolution during the DYNAMO campaign for the three MJO events in 2011. Radars of varying wavelengths operated throughout DYNAMO. Four of the radars were located on land sites and two were located on ships. Three land radars-the Shared Mobile Atmospheric Research and Teaching Radar (SMART-R), the S-PolKa (S-band and Ka-band dualpolarmetric radar), and the Ka-band ARM zenith radar (KAZR)-were located on the Addu Atoll of the Maldives within the Indian Ocean. The fourth land radar, the C-band scanning Atmospheric Radiation Measurement (ARM) precipitation radar (CSAPR)], was located on Manus Island in the western Pacific Ocean. One of the ship-based radars was aboard the R/V Mirai, and the other, Revelle, was located on the Roger Revelle (Yoneyama et al. 2013). Scatterometers, including ASCAT ( $\mathrm{C}$ band) and OSCAT (Ku band), provided good coverage for ocean surface wind condition during DYNAMO. Enhanced upper-air soundings and surface observations via buoy, ship, and surface stations across the Indian Ocean and Maritime Continent were collected by DYNAMO. There was a higher concentration of data collection on the eastern and western edges of the DYNAMO domain, as well as in East Africa and on Manus Island in the western Pacific Ocean
(Yoneyama et al. 2013), allowing researchers to see how the convective signal of an MJO event progressed through the entirety of its existence. In this study, we assimilated the surface observations, upper-air soundings, ASCAT/OSCAT wind, and radar data collected by DYNAMO into the WRF Model. Figure 2a shows the locations of the surface and upper-air observations that have been assimilated into the October experiment. Because of coverage and data availability, this study assimilated only the S-PolKa and Revelle radar data (radar sites shown in Fig. 2a). Figures 2b,c display sample data of Revelle radar radial velocity and ASCAT/OSCAT ocean surface wind that were assimilated for the December experiment.

\section{b. WRF Model simulation and data assimilation}

The Advanced Research version of WRF, version 3.5.1, was used to simulate the mesoscale convection during the onset of the October and December MJO events. The WRF Model setup can be seen in Fig. 2a with grid spacings of 9,3 , and $1 \mathrm{~km}$. The 9-km domain is referred to as "d01," the 3-km domain as " $\mathrm{d} 02$," and the 1-km domain as "d03." Since the simulation focused on the vast surface of the central Indian Ocean, where conventional observations are sparse, the initial condition of WRF Model contains errors and uncertainties. Through data assimilation methods, many of the DYNAMO observations that are not routinely available to operational centers (e.g., the National Centers for Environmental Prediction, the European Centre for Medium-Range Weather Forecasts) were subsequently included in an updated initial condition dataset. This updated initial condition, obtained through an assimilation step, is used to begin our WRF Model simulations. The WRF three-dimensional variational data assimilation (3DVAR; Barker et al. 2004) generated the representative input files for use in the E2ES. To this end, the field observations from DYNAMO provide a better WRF Model initial condition for mesoscale convection. Comparison results (not shown) showed positive impact of the DYNAMO data on WRF simulations for both the October and December experiments.

The DYNAMO upper-air and surface observations were assimilated using already available forward operators in WRF 3DVAR. Doppler radar data were assimilated with WRF 3DVAR following the methodology of Xiao et al. $(2005,2007)$. The scatterometer data were assimilated into the WRF Model following a methodology similar to that described in $\mathrm{Li}$ and $\mathrm{Pu}$ (2008).

A WRF control simulation was conducted with no data assimilation, which was used as the background field for the WRF 3DVAR. The NCEP Final Analyses (NCEP FNL) from the National Center for 

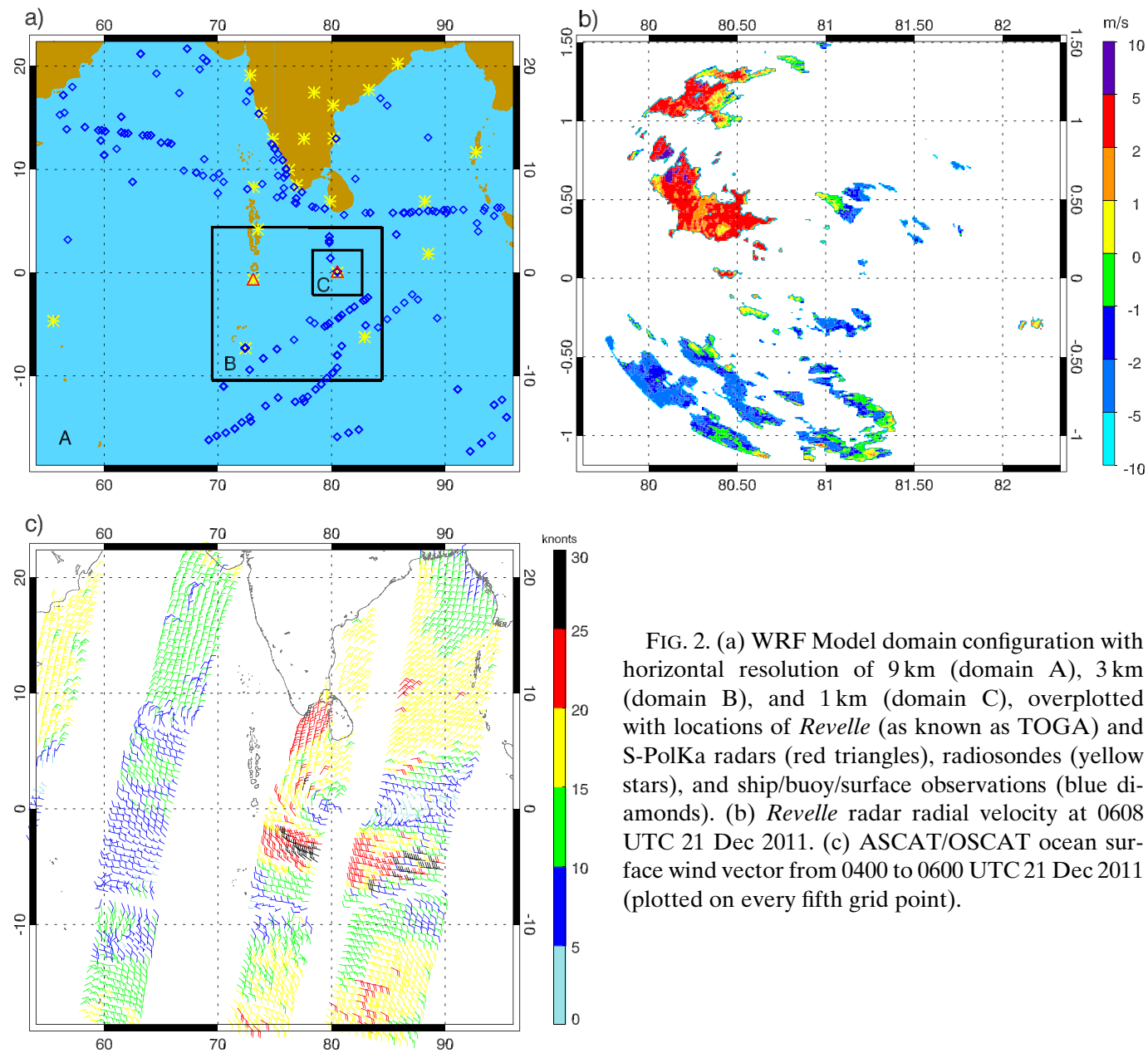

FIG. 2. (a) WRF Model domain configuration with horizontal resolution of $9 \mathrm{~km}$ (domain A), $3 \mathrm{~km}$ (domain B), and $1 \mathrm{~km}$ (domain C), overplotted with locations of Revelle (as known as TOGA) and S-PolKa radars (red triangles), radiosondes (yellow stars), and ship/buoy/surface observations (blue diamonds). (b) Revelle radar radial velocity at 0608 UTC 21 Dec 2011. (c) ASCAT/OSCAT ocean surface wind vector from 0400 to 0600 UTC $21 \mathrm{Dec} 2011$ (plotted on every fifth grid point).

Atmospheric Research (NCAR) were used for the initial condition of the WRF control simulation. The time frames analyzed with WRF modeling for the October and December MJO events were narrowed down to a few hours each to better examine the intricate finer details of the ocean surface wind dynamics. The focus of the WRF modeling was specifically on when precipitation was most abundant during the MJO events within the DYNAMO domain. Specifically, the start times of the October and December experiments were chosen based on the occurrence of WWBs that were observed during DYNAMO. The time frame for WRF modeling and other analyses was determined by locating regions of enhanced convection in infrared (IR) imagery from Meteosat-7 (channel 8, $11 \mu \mathrm{m}$ ). For the October MJO, data from 1 October to 1 November 2011 were selected for analysis, and for the December MJO, data from 15 December 2011 to 15 January 2012 were selected. The one month of data for each event (all of October, and from mid-December to mid-January) were needed to develop background error covariance matrices needed for WRF 3DVAR using the so-called National Meteorological Center (NMC)'s method (Parrish and Derber 1992), while other weather information was used to assess both MJO events, before focusing on more specific 24-h periods for running the WRF forecasts as inputs into the E2ES.

For the October experiment, the WRF Model's control run was initialized at 0000 UTC 26 October 2011. Using the 3-h forecast of the WRF control run as the first-guess field, cycled assimilation of the DYNAMO data was applied at an interval of every $3 \mathrm{~h}$ within a 12-h assimilation window. Hence, in each cycle, surface, sounding, and ASCAT/OSCAT data, available within $\pm 1.5 \mathrm{~h}$ from the analysis time were assimilated. The radar observations had a high frequency of $\sim 6$-min temporal resolution. The observations closest to the assimilation window were assimilated. After the cycled assimilation, a 12-h WRF forecast was conducted from 1200 UTC 26 October to 0000 UTC 27 October. To retrieve a high temporal depiction of the WWB, WRF output for the October event were produced every $3 \mathrm{~min}$ 
for $2 \mathrm{~h}$ starting at 1200 UTC. The simulation of the December MJO event began at 0000 UTC 21 December 2011. The data assimilation strategy for the December event was similar to that of the October event. Once the cycled assimilation process was complete, the WRF Model ran for $12 \mathrm{~h}$, until 0000 UTC 22 December. WRF outputs for the December event was produced every $30 \mathrm{~min}$. The use of 12-h data with a 30-min interval afforded broader spatial coverage of CYGNSS from the E2ES, and provide an opportunity to investigate the impacts of temporal resolution and spatial coverage on CYGNSS data. The WRF forecast files with assimilation of DYNAMO data were used as inputs for the CYGNSS E2ES and treated as "truth" to determine and analyze CYGNSS-observed winds.

\section{c. The E2ES}

It is important to know in advance how mesoscale and convective processes appear from the point of view of CYGNSS. To assess CYGNSS capabilities before the satellite was launched, members of the CYGNSS Science Team created the E2ES (O'Brien et al. 2015). This detailed simulator is capable of duplicating satellite orbit patterns and the various configurations in which each satellite can be placed. The E2ES was created based on the UK-DMC, which had very similar capabilities to CYGNSS and also produced DDMs of data. CYGNSS was placed in a lower orbit $(513-550 \mathrm{~km})$ and has higher gain $(14 \mathrm{~dB} i)$ than the UK-DMC, so it is designed to retrieve a larger range of wind speed data because it will have better sensitivity to any changes in ocean surface conditions (Ruf et al. 2016). CYGNSS is designed to observe a wide range of wind speeds within tropical cyclones. These simulated winds have root-mean-square error characteristics that match mission requirements: $2 \mathrm{~m} \mathrm{~s}^{-1}$ for winds at or below $20 \mathrm{~m} \mathrm{~s}^{-1}$ and $10 \%$ of the wind speed for winds above $20 \mathrm{~m} \mathrm{~s}^{-1}$ (Ruf et al. 2016). CYGNSS is the first space-based GNSS reflectometry (GNSS+R) constellation system.

The WRF Model output fields were prepared and put into a format that E2ES can process. The mandatory variables for E2ES input include time, latitude, longitude, wind speed ( $u$ and $v$ components), rain rate, freezing-level height, land mask, SST, and sea surface salinity. These input data were defined over a rectangular latitude-longitude area. Hence, all input variables, except salinity, were taken from the WRF simulations. As salinity has only a small effect on CYGNSS signals and was not available from the WRF simulations, it was set to a constant, domain-consistent average value of 35 psu for the E2ES input data.

The E2ES is able to adjust various settings, such as satellite configurations, and the outputs are separated into eight files that represent data from the individual satellites. The simulator was designed to create outputs as realistic as possible by accounting for rain attenuation and range corrections. The orbits and antenna pattern can be altered, as well as the construction of a DDM, noise levels, power levels, and even the time range of simulations. For this study, the E2ES configuration was set to defaults that mimicked the planned prelaunch orbits and sampling parameters for the constellation. The E2ES consists of several modes of operation that provide various outputs. This study used the dynamic mode, which represents a full simulation that includes the entire GPS and CYGNSS constellation's orbits with time-varying wind fields. A 1-s sampling frequency for each CYGNSS observatory was set, with the top four specular points [based on range-corrected gain (RCG)] in each sampling interval recorded for each observatory [see Ruf et al. (2013a) for the definitions of specular points and specular tracks]. Thus, the 30-min- or 3-minresolution WRF Model output was time interpolated to 1-s resolution for use in the E2ES. This 1-s data rate is identical to how CYGNSS operates in reality.

The CYGNSS E2ES was run using the "fast" setting, which does not produce individual DDMs. Instead, the E2ES in fast mode uses orbital calculations to select grid points and then produces simulated retrieved winds for the 25-km footprint of each CYGNSS specular point. The effects of noise are simulated using a lookup table that greatly reduced the computational requirements. This study analyzed the geolocated Level 2 wind speeds for all specular points produced by the E2ES.

\section{Results}

\section{a. October $2011 \mathrm{MJO}$}

Figure $3 \mathrm{a}$ shows the number of cold $\sim 11-\mu \mathrm{m}$ IR brightness temperature $(<220 \mathrm{~K})$ pixels counted between $20^{\circ} \mathrm{S}$ and $20^{\circ} \mathrm{N}$ in Meteosat-7 imagery in a Hovmöller diagram. Enhanced convection spread across the Indian Ocean and an eastward propagation can be seen from 21 to 31 October 2011. A regional WRF simulation was conducted for the enhanced precipitation from 0000 UTC 26 October to 0000 UTC 27 October 2011. In this section, we focus on analysis of the WRF Model's 9-km domain. CYGNSS E2ES-simulated wind was generated using a 3-min interval of WRF 9-km grid spacing output from 1200 to 1400 UTC 26 October 2011.

\section{1) WRF MODEL FORECAST FIELDS}

Figures $4 \mathrm{a}-\mathrm{e}$ show WRF's forecast of reflectivity and its 10-m wind field from 1203 to 1357 UTC 26 October 2011. The reflectivity structures show that the WRF-simulated convective storms tended to be quasi-organized systems 

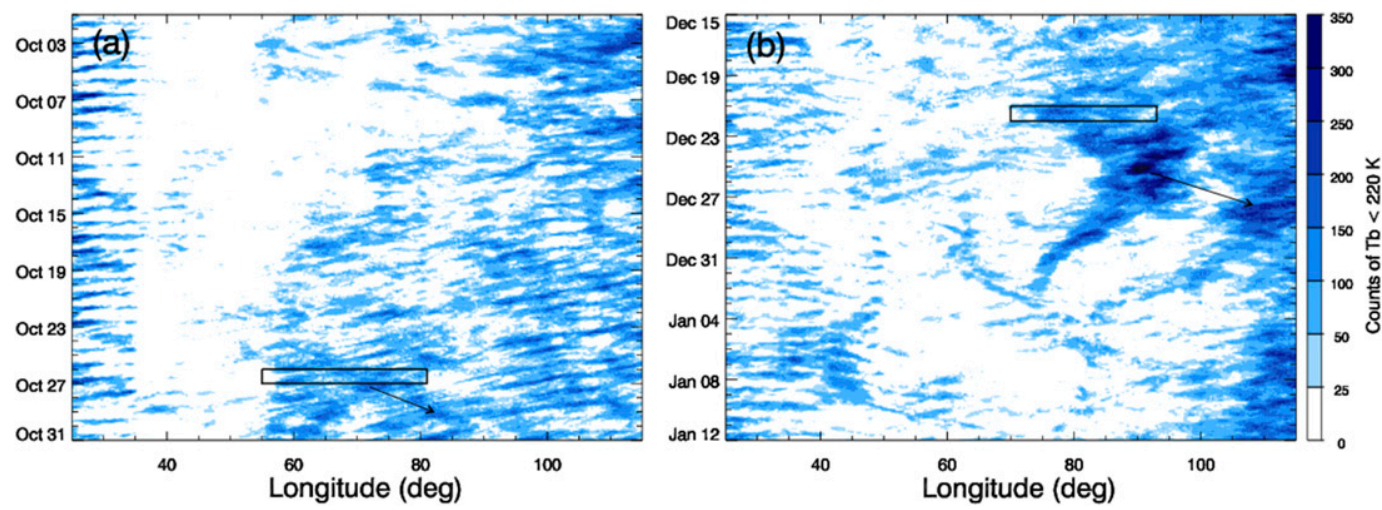

FIG. 3. A longitude vs time Hovmöller diagram of Meteosat-7 $\sim 11-\mu \mathrm{m}$ IR brightness temperature (channel 8) (a) from 1 to 31 Oct 2011 and (b) from 15 Dec 2011 to 12 Jan 2012. The number of points with an IR brightness temperature less than $220 \mathrm{~K}$ was counted to determine the location of colder, higher clouds, which indicate active convective storms and precipitation. The black box indicates the location and time frame of enhanced precipitation (a) from 0000 UTC 26 Oct to 0000 UTC 27 Oct 2011 and (b) from 0000 UTC 21 Dec to 0000 UTC 22 Dec 2011. The arrows represent the eastward propagation of convection.

with embedded smaller-scale storms. There is a gradual eastward propagation of the storm cells near the equator. A semi-bow-like feature was centered around $5^{\circ} \mathrm{N}, 75^{\circ} \mathrm{E}$. A sustained zonal wind of $5 \mathrm{~m} \mathrm{~s}^{-1}$ and above can be seen in the vicinity of the convective cells. Figure 5 provides the derived low-level convergence and upper-level divergence from the Meteosat-7 satellite (data obtained from the University of Wisconsin's Cooperative Institute for Meteorological Satellite Studies) at 1200 UTC 26 October 2011 to indicate the accuracy of the WRF forecast. Strong low-level convergence (Fig. 5a) was observed in the region of $0^{\circ}-10^{\circ} \mathrm{N}, 60^{\circ}-80^{\circ} \mathrm{E}$. The patterns in Fig. $5 \mathrm{~b}$ show that there was also strong divergence within the same region where WRF simulated strong convection and precipitation. These long-lived, organized convective storms (i.e., MCSs), as generated in the WRF simulation, occurred within the larger, synoptic-scale WWBs, resulting in meso- $\beta$-scale $(25-250 \mathrm{~km})$ regions of enhanced westerly winds. Moum et al. (2014) indicated that WWBs were observed in October and December 2011 MJO events. Our 8-day WRF forecast from 22 to 30 October (not shown) also produced synoptic-scale regions of sustained westerlies (with a zonal wind of $5 \mathrm{~m} \mathrm{~s}^{-1}$ and above) covering portions of the central Indian Ocean near the equator, which we associate with WWBs.

\section{2) CYGNSS E2ES FIELDS}

For the CYGNSS E2ES, each satellite track is different and is not guaranteed to pass over a particular area at a specific time. The simulator provided the ability to manually input the simulator start time and the orbit start time. To guarantee a CYGNSS overpass occurred during the 2-h analysis period, the E2ES simulation start time and the CYGNSS orbit start time were manually adjusted relative to one another, with the former starting at 1200 UTC but the latter starting at 0750 UTC 26 October. The WRF Model output fields were ingested into the E2ES from 1200 to 1400 UTC 26 October 2011 and then the simulator was operated at 1-s increments. We are particularly interested in how CYGNSS performs in regions with high variations in wind and in the presence of precipitation. Figure $6 a$ shows the specular tracks from all eight CYGNSS satellites between 1200 and 1400 UTC. The background image in Fig. 6a is the ingested WRF wind field at 1300 UTC. The dots across the map represent wind retrievals at specular points from the CYGNSS overpasses as made by the E2ES. As shown in Fig. 6a, increased wind speeds can be found throughout the WWB, despite the heavy precipitation in this region.

\section{3) WRF IN COMPARISON TO CYGNSS}

For the forthcoming comparisons, three individual specular point tracks (tracks 12,97, and 51) from three different CYGNSS observatories $(1,4$, and 8$)$ were analyzed (Fig. 7a). These selected tracks intersected the WWB region and could indicate the potential effects of CYGNSS observations for convection. Figures $7 b, c, d$ compare the winds along each CYGNSS track to the "true" WRF winds (i.e., WRF winds remapped to CYGNSS observing geometry but without the addition of any noise or other measurement errors) at the same location. CYGNSS wind speed data are relatively noisy in comparison to WRF-simulated winds and thus two smoothing methods were examined to investigate how these may benefit CYGNSS observations. The first smoothing method was the forward-back method, which filtered the winds twice along each specular point track. 

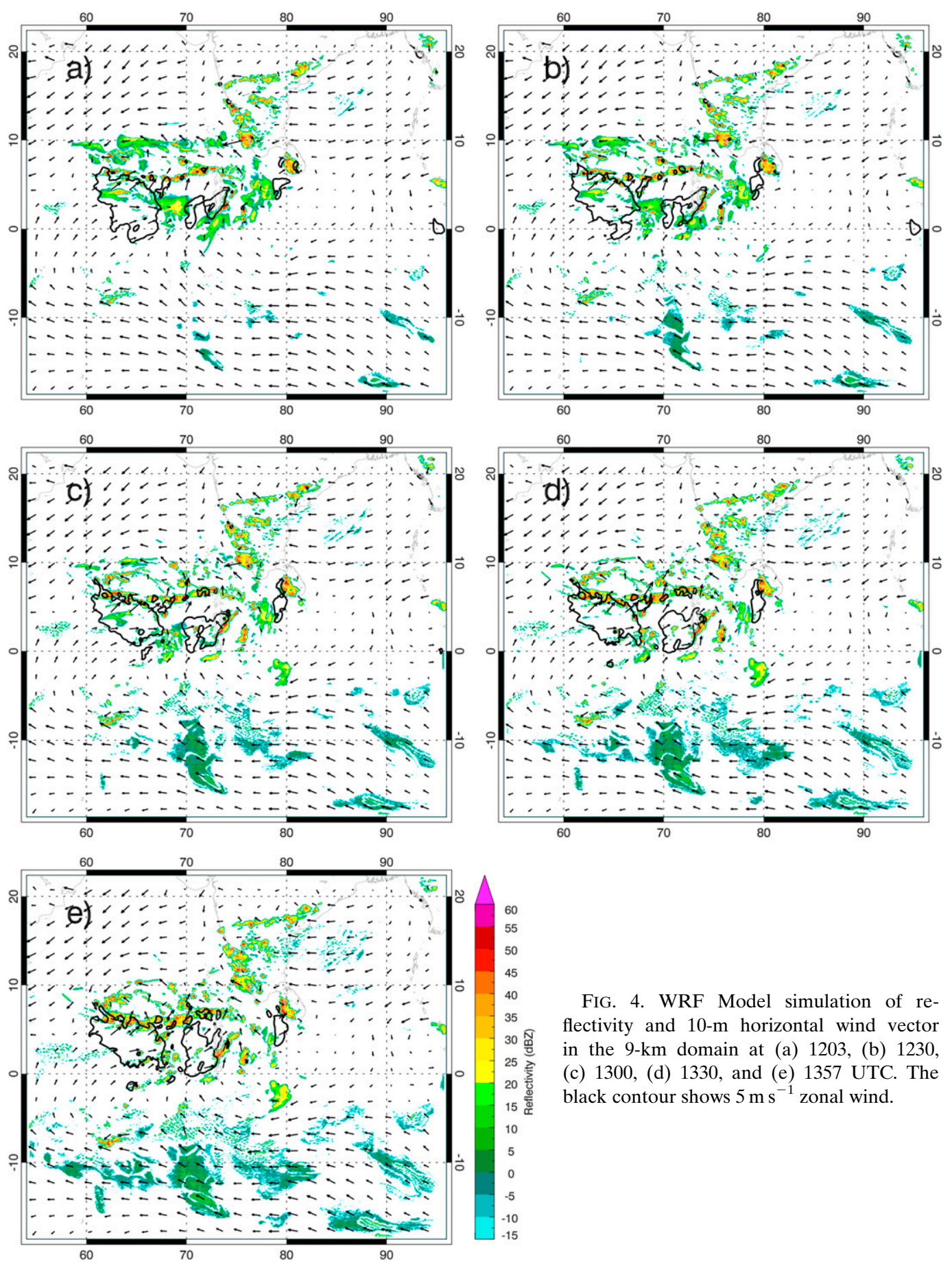

FIG. 4. WRF Model simulation of reflectivity and $10-\mathrm{m}$ horizontal wind vector in the 9-km domain at (a) 1203, (b) 1230, (c) 1300, (d) 1330, and (e) 1357 UTC. The black contour shows $5 \mathrm{~m} \mathrm{~s}^{-1}$ zonal wind.

The first application of the filter accounted for the average wind speed of the data at the first point plus the four points ahead of it, using a forward progression for each point in the track until the end was reached. The second filtering application went backward, accounting for the average of the new value at a point plus the new values of the four points that occurred before it, and became the new, and final, wind speed value for that point. Effectively then, two passes of a five-point boxcar filter were applied in different directions along the track. The second smoothing method was a more common five-point centered boxcar filter.

Track 12 (Fig. 7b) passed over the WWB around 1233 UTC. The WRF winds increased to over $10 \mathrm{~m} \mathrm{~s}^{-1}$ at 

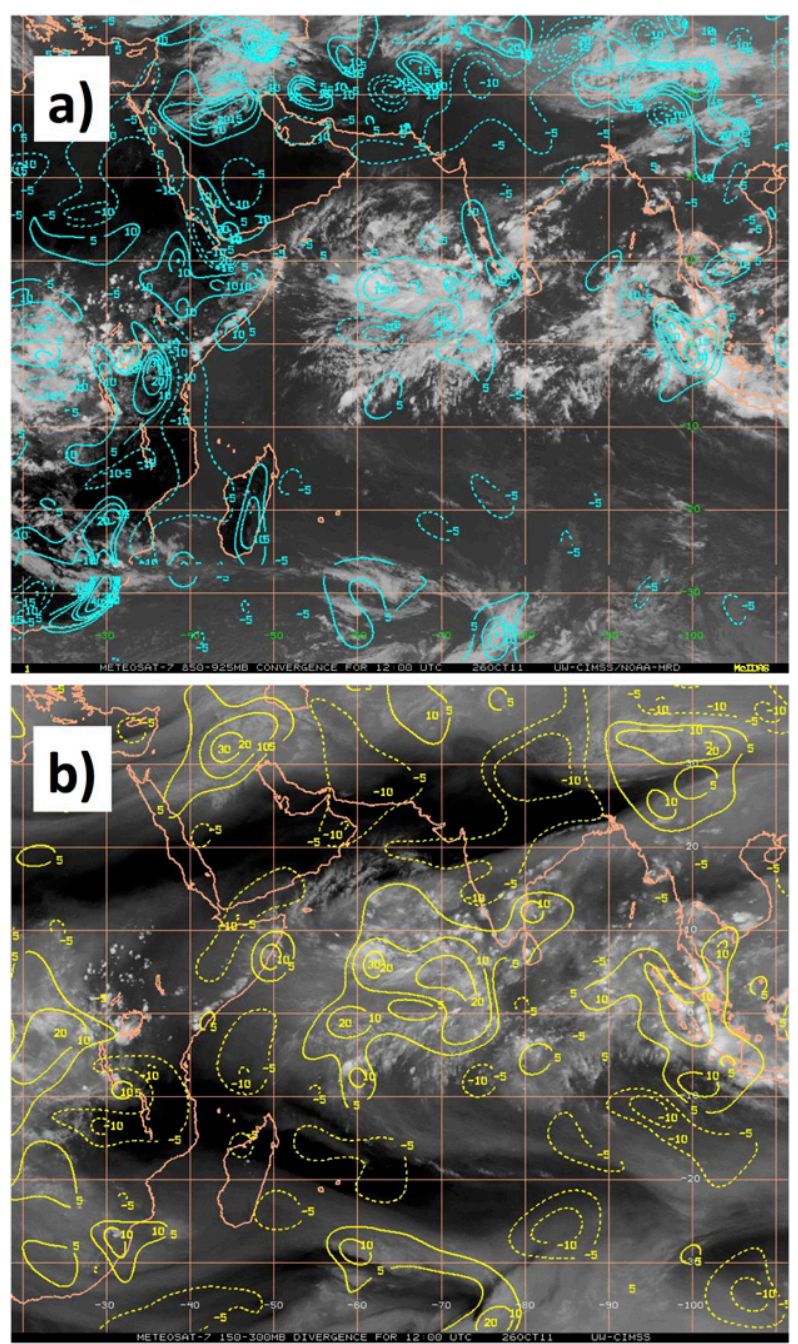

FIG. 5. (a) Meteosat-7-derived low-level convergence and (b) Meteosat-7-derived upper-level divergence at 1200 UTC 26 Oct 2011.

peak strength along the track. Unfiltered CYGNSS observations generally followed the same pattern but with significant noise, particularly along the first half of the track. This was due to reduced RCG in that region, an issue that will be revisited later. RCG represents an improved definition of gain that takes into account both the effect of the receiver antenna and the effect of attenuation caused by range losses (Ruf et al. 2016). As the specular points moved toward a more centered location in the CYGNSS antenna pattern, RCG increased and reduced the noise in the retrieved winds. Either filtering method significantly improved the agreement with the truth winds.

Tracks 97 (Fig. 7c) and 51 (Fig. 7d) nearly overlapped spatially within the WWB (located near $5^{\circ} \mathrm{N}, 61^{\circ}-68^{\circ} \mathrm{E}$ ) but were approximately $50 \mathrm{~min}$ apart. This presented an opportunity to examine temporal evolution in that location. The truth WRF winds showed limited variability during that period, highlighting the stability of the WWB feature. In both plots, CYGNSS, especially when filtered, characterized sharp gradients in the truth wind speed amidst an overall increase in wind strength associated with the WWB. In addition, RCG improved farther east along both tracks and thus the relative impact of filtering was reduced.

A representative example of the relationship between winds along CYGNSS specular point tracks and convective structure and evolution is shown in Figs. 8a-c. Simulated radar reflectivity and winds along a specific CYGNSS track (both obtained via a nearest-neighbor interpolation approach) before, during, and after the overpass show how the leading-edge gust front responds to convective evolution. At 1206 UTC (Fig. 8a), before the CYGNSS overpass along this track, there is a broad increase in wind speeds near $75.5^{\circ} \mathrm{E}$ (along the track) associated with developing convection. The CYGNSS overpass occurs during the beginning of the mature stage (1245 UTC; Fig. 8b), when the gust-front wind speed gradient has sharpened while the convective system has developed a downdraft. CYGNSS observes the essential character of this gradient.

While overall the simple five-point moving boxcar average applied to the track improves the match to the WRF winds, along the gust front the gradient is so sharp that the unfiltered CYGNSS winds are more representative in the convection itself. CYGNSS accurately measures this wind shift despite the deep core of high reflectivity (and thus heavy rainfall) across the front.

After the overpass (1336 UTC; Fig. 8c), the convective system/MCS has further matured and broadened in size, and the wind speed gradient across the gust front is reduced. The wind speed maximum also is more closely aligned with the heaviest precipitation. With this analysis occurring only along a track, the observed evolution may reflect the movement of the convection across the track convolved with the temporal evolution of the convection itself. However, it is clear that key characteristics of the various stages of tropical convective system development (e.g., Rowe and Houze 2014) are reproduced by this way of analyzing the twodimensional WRF dataset, which closely matches how CYGNSS will sample.

\section{b. December 2011 MJO}

Similar to Fig. 3a, the number of cold $11-\mu m$ IR brightness temperature $(<220 \mathrm{~K})$ pixels counted between $20^{\circ}$ and $20^{\circ} \mathrm{N}$ from Meteosat-7 imagery in Fig. 3b revealed convective activity across the DYNAMO domain from 15 to 31 December 2011. The enhanced 
(a) $10 / 26 / 2011$ 1200-1400 UTC

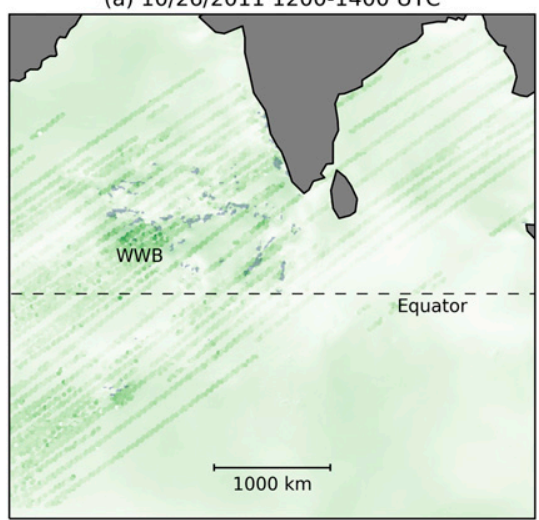

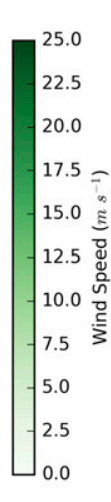

(b) $12 / 21 / 2011$ 1200-0000 UTC

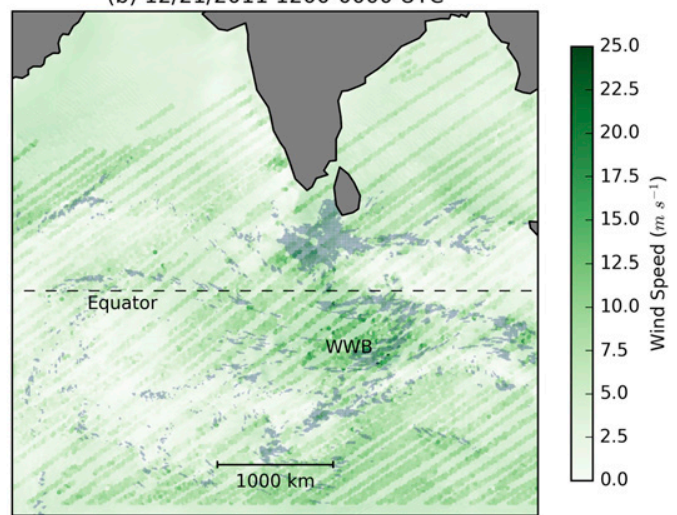

FIG. 6. CYGNSS E2ES wind speeds (dots) (a) plotted for 1200-1400 UTC, overlaid on WRF wind speed (faded background colors) at 1300 UTC 26 Oct 2011 and (b) plotted for 1200 UTC 21 Dec-0000 UTC 22 Dec 2011, overlaid on WRF wind speeds (faded background colors) at 1800 UTC 21 Dec 2011. Also indicated are areas of $>10-\mathrm{mm}$ accumulated precipitation (hatched blue shading), the approximate locations of the two WWBs described in the text (enhanced wind speed regions), the equator, and the map scale.

activity began near the S-PolKa radar site $\left(73.1^{\circ} \mathrm{E}\right)$ on 21 December 2011. The region of enhanced precipitation had a slow eastward progression near the equator throughout the latter half of December. Because of the widespread activity on 21 December, a WRF Model simulation was conducted between 0000 UTC 21 December and 0000 UTC 22 December 2011. This section focuses on the period 1200 UTC 21 December-0000 UTC 22 December. The CYGNSS E2ES wind was generated for that period with a 30-min interval of WRF output. As the analysis of the October event was sufficient to demonstrate the ability of CYGNSS to detect convective wind features, the December experiment will delve into details on how temporal frequency and spatial coverage will influence this capability, and how it can potentially enable surface flux estimates when RCG is high.

\section{1) WRF MODEL FORECAST FIELDS}

Figure 9 shows the WRF Model forecast after assimilation of DYNAMO data from 1230 UTC 21 December to 0000 UTC 22 December 2011. A heavy precipitation system was predicted near $5^{\circ} \mathrm{N}, 78^{\circ} \mathrm{E}$ with an eastern propagation from 1230 UTC 21 December to 0000 UTC 22 December. It is also shown that a bowed-out line of enhanced convection centered near the equator intensified at 1830 UTC (Fig. 9c). The bowing line centered between $0^{\circ}$ and $4^{\circ} \mathrm{S}$ fell into the $5 \mathrm{~m} \mathrm{~s}^{-1}$ zonal wind contour. The $5 \mathrm{~m} \mathrm{~s}^{-1}$ zonal wind contour shows that the eastward-bowing precipitation line was moving eastward as a result of a WWB feature within the larger MJO convective envelope. The center of this bowing line was between $0^{\circ}$ and $4^{\circ} \mathrm{S}$. Figures $9 \mathrm{c}, \mathrm{d}$,e clearly indicated the eastward propagation of the line.
The convection strengthened during the period of simulation, in terms of areal coverage and the development of individual convective lines.

\section{2) CYGNSS E2ES FIELDS}

For the December experiment, a 12-h WRF forecast (1200 UTC 21 December-0000 UTC 22 December) with 30-min output frequency was applied to CYGNSS E2ES. With this strategy, the E2ES wind has a coarser temporal resolution but with broader spatial coverage. This allows us to examine how the temporal frequency and spatial coverage influence CYGNSS wind. All specular point tracks from the 12 -h period are combined and shown in Fig. 6b. The CYGNSS data indicated large-scale regions of enhanced wind speeds, even in the presence of heavy precipitation. In Fig. $6 b$, the faster winds within the WWB were located in the region of $4^{\circ} \mathrm{N}-8^{\circ} \mathrm{S}, 74^{\circ}-86^{\circ} \mathrm{E}$. The detailed analysis and evaluation of CYGNSS wind was narrowed to focus on a WWB (indicated in Fig. 6b) in the time frame of 1730-1930 UTC 21 December 2011.

Seven individual specular point tracks from six different CYGNSS observatories (track 1 from observatory 1 , tracks 2 and 3 from observatory 2 , track 4 from observatory 3 , track 5 from observatory 4 , track 6 from observatory 7 , and track 7 from observatory 8 ) were analyzed (Fig. 10). The tracks (encircled in red in Fig. 10) traveled from the southwest portion of the domain to the northeast while passing over a diverse wind field that contained wind speeds from near zero to approximately $20 \mathrm{~m} \mathrm{~s}^{-1}$. The WWB location correlates with the center of the bowed convection line seen in Fig. 9. The eastern edge of the wind gradient was collocated with the leading line of convection seen in the 
(a) WRF (1300Z) \& CYGNSS (Tracks $12,51,97)$

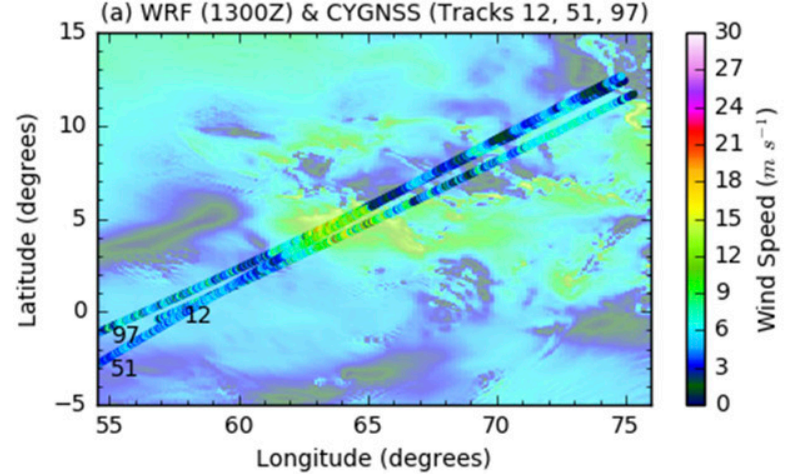

(b) Track 12, 1233 UTC, Median RCG $=66.0$
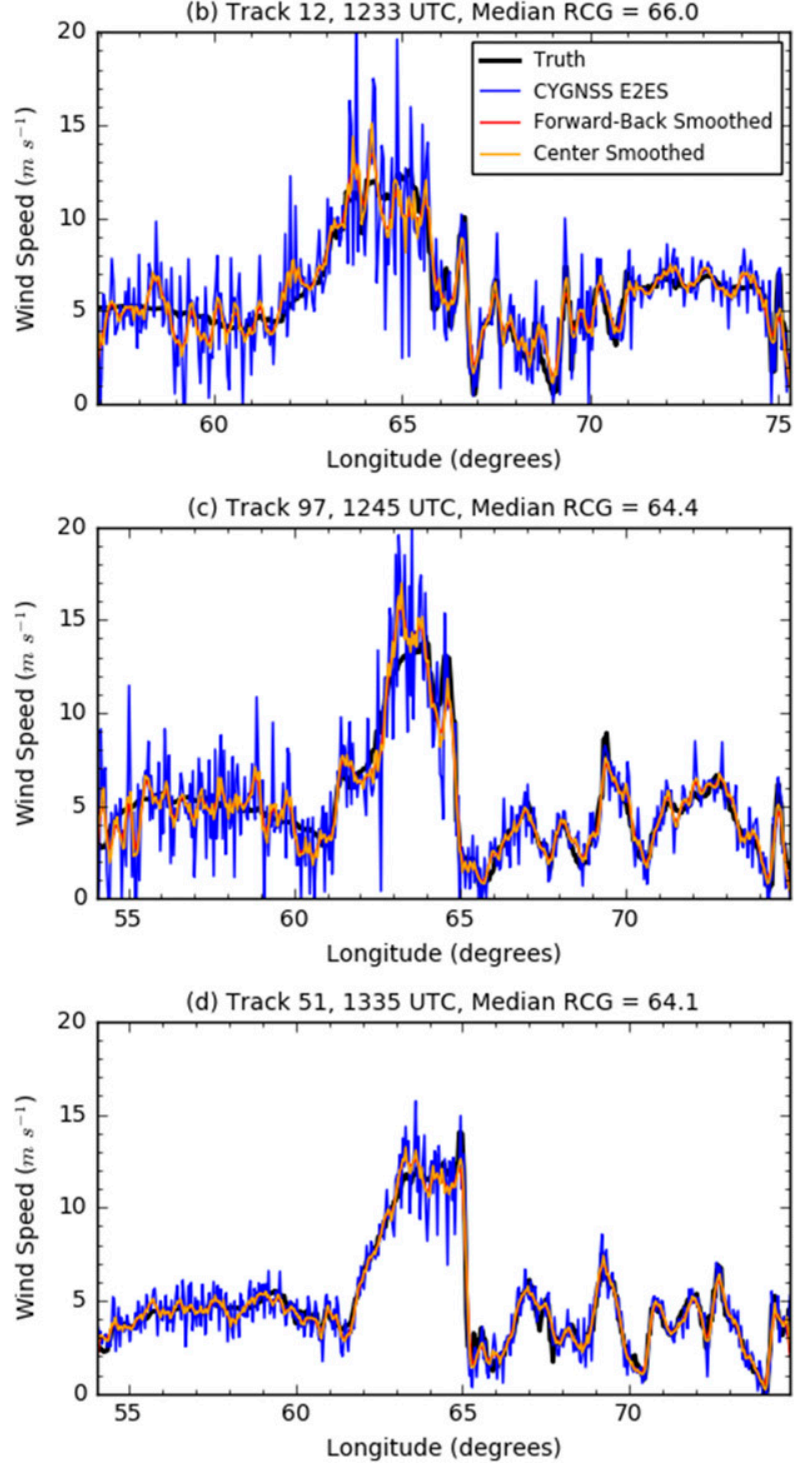

FIG. 7. (a) WRF 10-m wind speeds (faded colors) at 1300 UTC with three CYGNSS specular point tracks (arbitrarily numbered 12, 51, and 97) overlaid (colored dots). The specular tracks all cross over the WWB near $5^{\circ}$ N. (b) Series plot for track 12 (formed by CYGNSS observatory 1 and GPS satellite 30), with truth winds, unfiltered CYGNSS winds, and CYGNSS winds
WRF modeled reflectivity. The sharp gradient in the specular points, with approximately $6-7 \mathrm{~km}$ between each point, along the gust front reflected the sharp gradient seen in the truth WRF wind. The specular points showed qualitatively that the CYGNSS data were fairly agreeable with the WRF-generated winds and that there appears to be no degradation of wind speed retrievals within areas of known precipitation.

\section{3) WRF IN COMPARISON TO CYGNSS}

The CYGNSS-simulated winds for the seven selected tracks that crossed the convective gust front were compared to the 1-km domain WRF winds. WRF Model winds and raw E2ES-simulated CYGNSS winds are plotted against each other in the left panels of Fig. 11, along with CYGNSS winds filtered using the two different filtering methods described above.

Tracks 3-7 (Figs. 11e-n) captured the strongest wind speed gradients, while tracks 1 and 2 (Figs. 11a-d) captured winds where the gust front was weaker. These plots revealed that the CYGNSS winds were prone to having high variability between consecutive points in a single track. The normalized root-mean-square error (NRMSE) for the simulated wind speeds was $25.4 \%$. In reality, winds across an area were smoother than what the simulated CYGNSS was producing. By smoothing the winds via the centered smoothing method and the forward-back smoothing method, the NRMSEs were reduced to $13.9 \%$ and $12.4 \%$, respectively. The smoothed winds were more realistic and less noisy than the unsmoothed winds. Table 1 lists the errors for each track and different smoothing methods. It is indicated that the forward-back (Fwd-Bk) method resulted in the lowest wind speed errors in comparison to the unsmoothed and center-smoothed winds. However, any smoothing was preferable to none.

Examining the plotted wind tracks and the corresponding errors, the simulated winds performed relatively well in some tracks (such as tracks 2 and 6) but poorly in others (such as tracks 1, 3, and 5). Table 1 also listed the mean RCG for each track. RCG is a function of where the specular point occurs relative to the

filtered by the two different methods described in the text. (c) Series plot for track 97 (formed by CYGNSS observatory 8 and GPS satellite 30), with truth winds, unfiltered CYGNSS winds, and CYGNSS winds filtered by the two different methods described in the text. (d) Series plot for track 51 (formed by CYGNSS observatory 4 and GPS satellite 15), with truth winds, unfiltered CYGNSS winds, and CYGNSS winds filtered by the two different methods described in the text. 

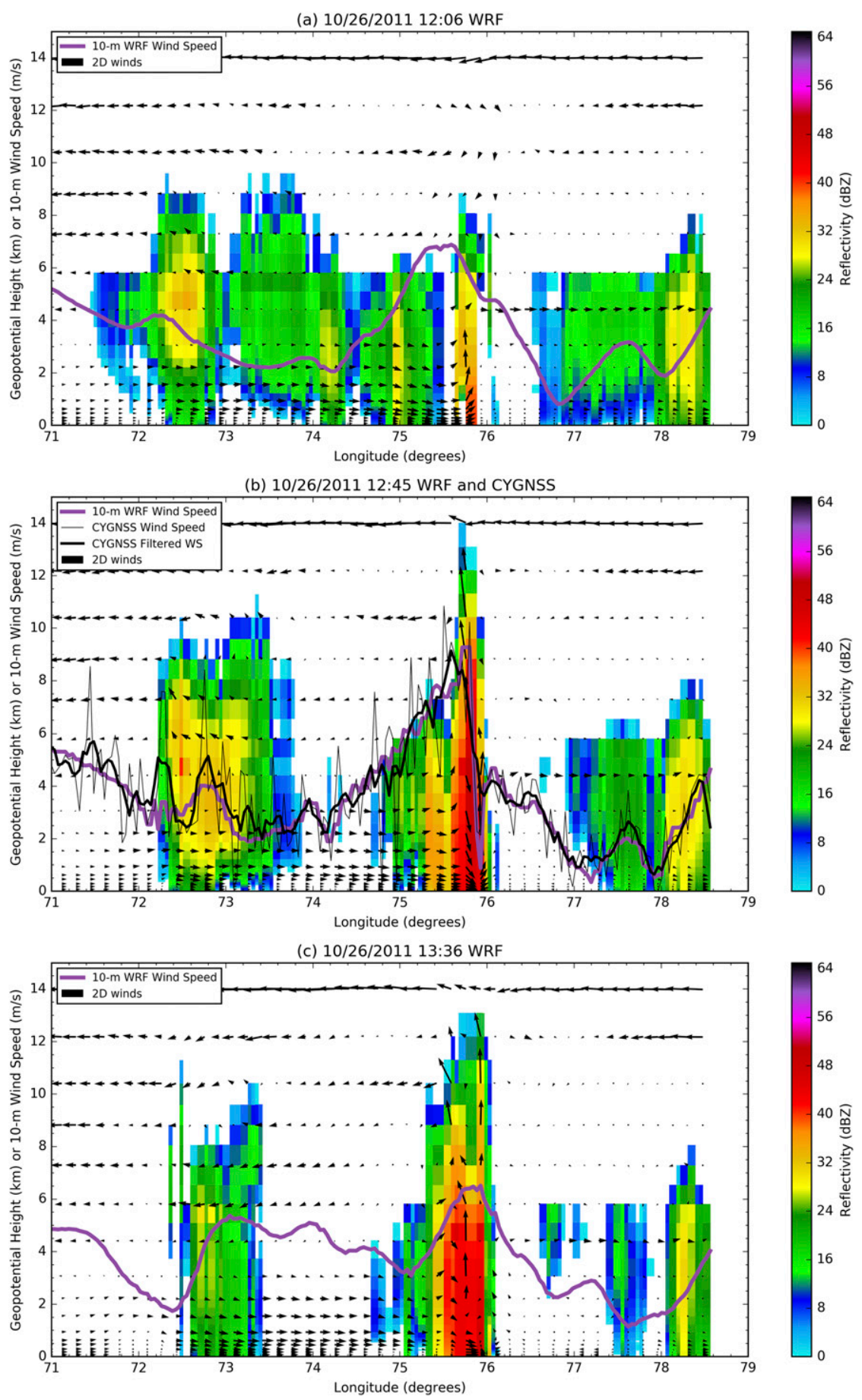

FIG. 8. Vertical cross section along a representative CYGNSS specular point track of WRF 10 -cm simulated radar reflectivity (colors), 10-m WRF wind speeds (purple), and 2D winds in the plane of the track (vectors) at three specific times on 26 Oct 2011. Vectors are for qualitative purposes only; they have been thinned by a factor of 2 in the vertical and a factor of 4 in the horizontal, and the vertical component has been magnified by a factor of 10. (a) 1206 UTC. (b) 1245 UTC, corresponding to the actual CYGNSS track occurrence. CYGNSS wind speed (raw and five-point boxcar filtered) is shown as well. (c) 1336 UTC. 

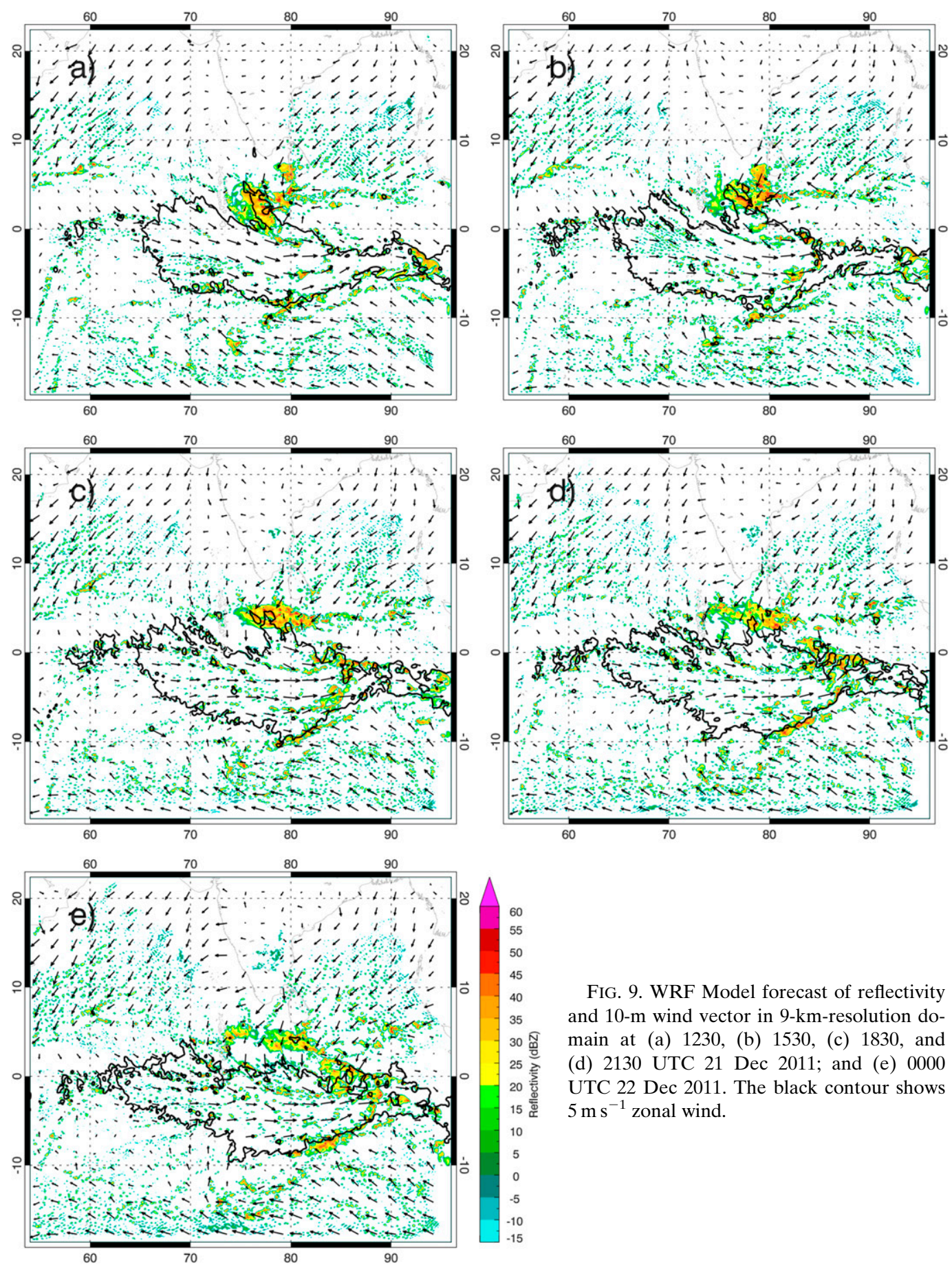

FIG. 9. WRF Model forecast of reflectivity and $10-\mathrm{m}$ wind vector in 9-km-resolution domain at (a) 1230, (b) 1530, (c) 1830, and (d) 2130 UTC 21 Dec 2011; and (e) 0000 UTC 22 Dec 2011. The black contour shows $5 \mathrm{~m} \mathrm{~s}^{-1}$ zonal wind.

antenna boresight-the closer to the center of the antenna boresight's footprint, the larger the RCG. Thus, low values of RCG resulted in greater errors within CYGNSS winds, while higher values of RCG resulted in more accurate wind retrievals. Generally, RCG needs to exceed $10 \mathrm{~m}^{-4}$ for the best results. High RCG also means filtering along the track does not provide as much improvement, as the raw wind speed errors are already low. The bias of these errors is $0.06 \mathrm{~m} \mathrm{~s}^{-1}$ for the CYGNSS-simulated winds in comparison to the truth WRF winds. Smoothing the data only minimally reduced the net bias to $0.05 \mathrm{~m} \mathrm{~s}^{-1}$ for both the center and forward-back methods. However, for low-RCG tracks, smoothing reduces errors by approximately a factor 


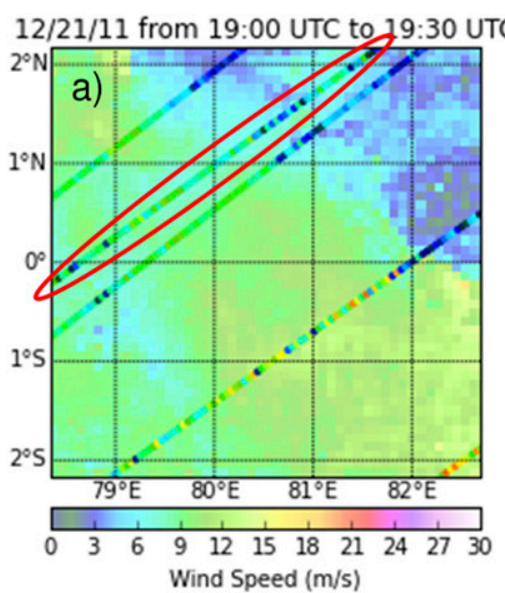

$12 / 21 / 11$ from 18:30 UTC to 19:00 UTC
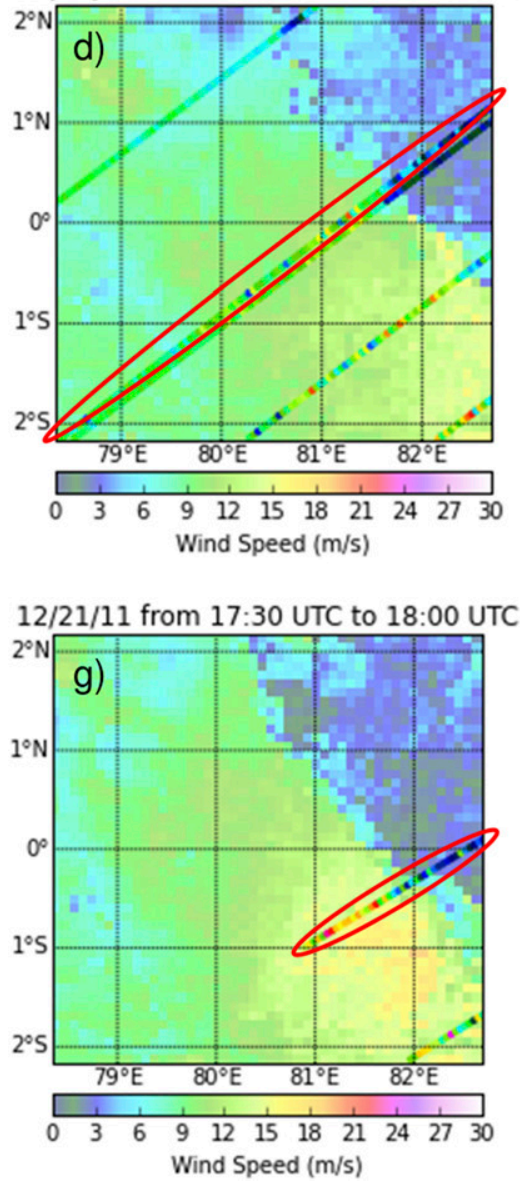

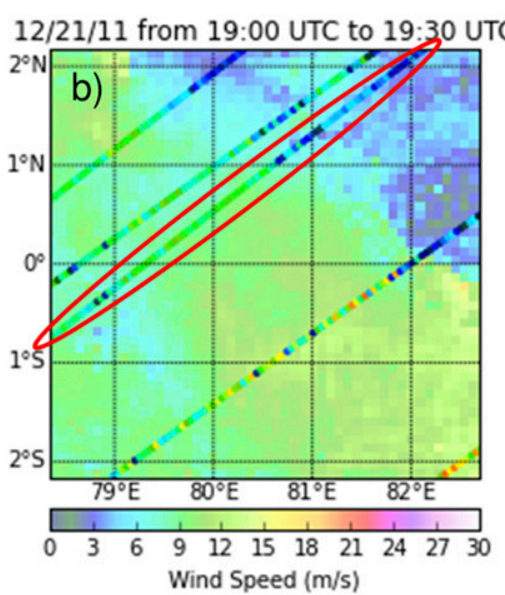

$12 / 21 / 11$ from 18:30 UTC to $19: 00$ UTC

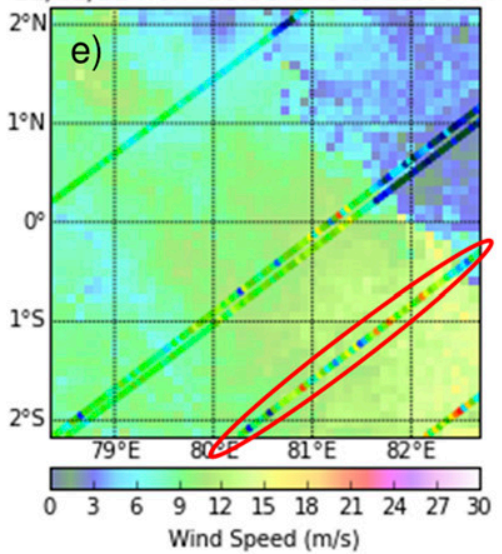

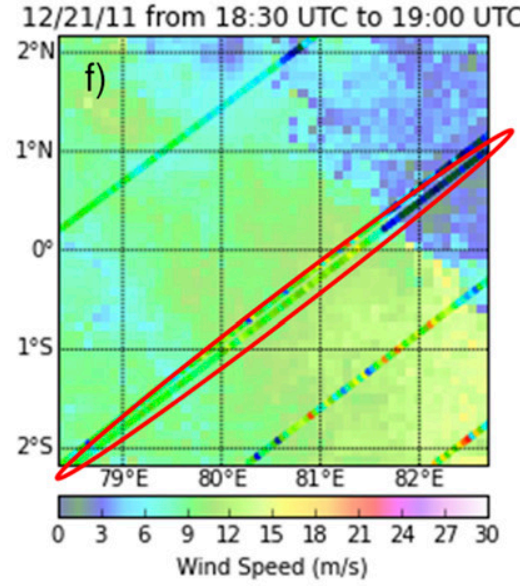

12/21/11 from 19:00 UTC to $19: 30$ UTC

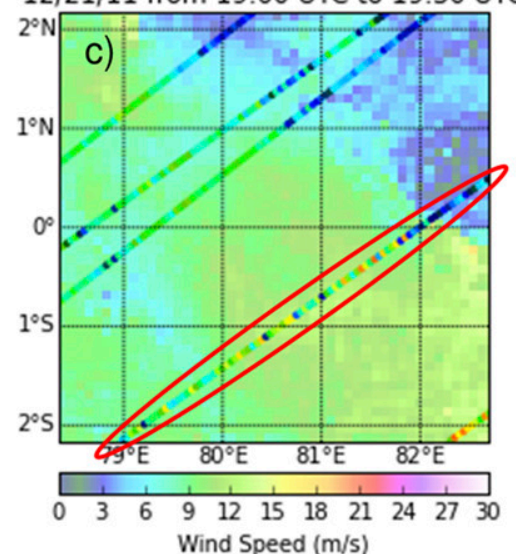

$12 / 21 / 11$ from 18:30 UTC to 19:00 UTC

FIG. 10. Specular points of the E2ES-simulated CYGNSS wind speeds overlaid on the assimilated WRF truth data $\left(\mathrm{m} \mathrm{s}^{-1}\right)$ on 21 Dec 2011. Maps are for (a) track 1, occurs from 1924:55 to 1926:12 UTC; (b) track 2, occurs from 1910:51 to 1912:22 UTC; (c) track 3, occurs from 1912:24 to 1913:49 UTC; (d) track 4, occurs from 1858:02 to 1859:46 UTC; (e) track 5, occurs from 1845:57 to 1846:56 UTC; (f) track 6, occurs from 1833:42 to 1835:18 UTC; and (g) track 7, occurs from 1755:54 to 1756:35 UTC. The date and times on the tops of all figure panels pertain to the WRF Model field times used as E2ES input.

of 2 or better. For example, the raw data for track 5 $\left(\mathrm{RCG}=2.5 \mathrm{~m}^{-4}\right)$ saw a reduction in RMSE from $35.6 \%$ to $17.5 \%$ if the forward-back filtering method was used.

Next, the simulated wind speeds were applied to an air-sea latent heat flux estimate following Abualnaja et al. (2015),

$$
Q_{e}=L \rho C_{e} U\left(q_{a}-q_{s}\right)
$$

to reveal how errors in the CYGNSS-observed surface winds will affect the surface flux. In this equation, $L$ is the latent heat of water, $\rho$ is air density, $C_{e}$ is the bulk transfer coefficient (also known as the Dalton number), 

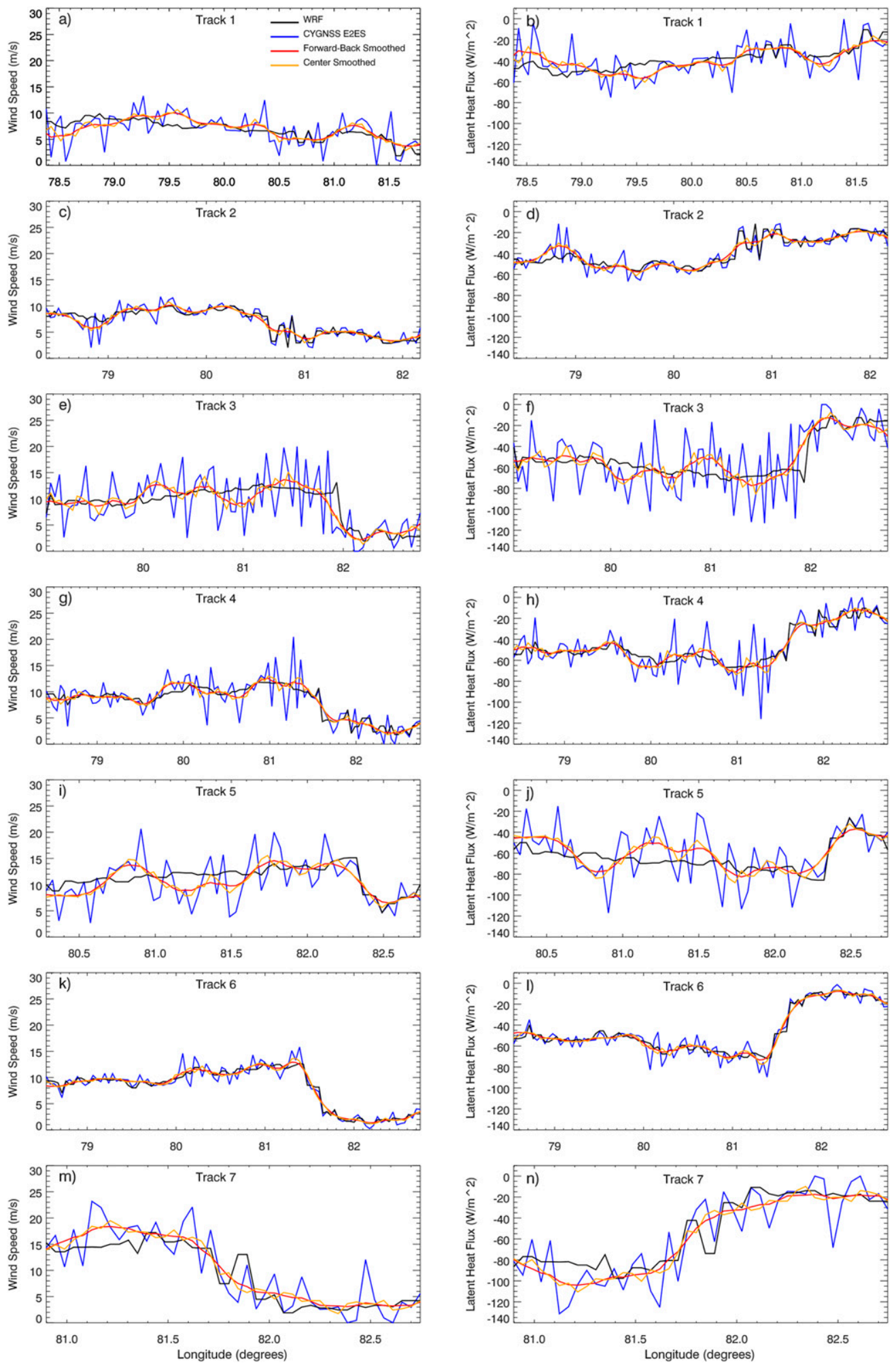

FIG. 11. (left) Wind speed $\left(\mathrm{m} \mathrm{s}^{-1}\right)$ and (right) latent heat flux $\left(\mathrm{W} \mathrm{m}^{-2}\right)$ with longitude for specular point (a), (b) track 1, (c),(d) track 2, (e),(f) track 3, (g),(h) track 4, (i),(j) track 5, (k),(l) track 6, and (m),(n) track 7 on 21 Dec 2011. 
TABLE 1. RMSE of the simulated CYGNSS wind speed data (unsmoothed or smoothed) of seven specular point tracks on 21 Dec 2011. Simulated: wind data, as is, from CYGNSS. Fwd-Bk: CYGNSS data smoothed using the forward-back method. Centered: CYGNSS data smoothed using the centered smoothing method. Mean RCG: Mean RCG is used to account for errors $\left(\mathrm{m}^{-4}\right)$ in the E2ES.

\begin{tabular}{lcccr}
\hline \hline & $\begin{array}{c}\text { Simulated } \\
(\%)\end{array}$ & $\begin{array}{c}\text { Centered } \\
(\%)\end{array}$ & $\begin{array}{c}\text { Fwd-Bk } \\
(\%)\end{array}$ & $\begin{array}{r}\text { Mean } \\
\text { RCG }\end{array}$ \\
\hline Track 1 & 31.2 & 16.5 & 16.0 & 1.5 \\
Track 2 & 15.4 & 12.5 & 11.4 & 11.2 \\
Track 3 & 37.5 & 15.8 & 13.2 & 1.3 \\
Track 4 & 23.7 & 10.3 & 9.0 & 6.4 \\
Track 5 & 35.6 & 20.0 & 17.5 & 2.5 \\
Track 6 & 9.5 & 6.1 & 5.2 & 40.7 \\
Track 7 & 24.9 & 16.2 & 14.4 & 1.2 \\
RMSE & 25.4 & 13.9 & 12.4 & \\
\hline
\end{tabular}

$U$ is wind speed, $q_{a}$ is the air specific humidity, and $q_{s}$ is the saturated specific humidity. The latent heat of water at $30^{\circ} \mathrm{C}$ was used, which is $2.425 \times 10^{6} \mathrm{~J} \mathrm{~kg}^{-1}$. The domain-averaged values calculated over the $1-\mathrm{km}$ WRF domain for air temperature $(300.8 \mathrm{~K})$, surface pressure $(100912 \mathrm{~Pa})$, and SST $(302.2 \mathrm{~K})$ were used in the computation of $\rho, q_{s}$, and $q_{a}$. The coefficient $C_{e}$ depends on the SST and wind speed at a location. As the wind speed changes at each point in a track, a generalized value is chosen. Typical values for $C_{e}$ lie between $1 \times 10^{-3}$ and $5 \times 10^{-3}$, where lower values are common over the ocean. In this equation, $2 \times 10^{-3}$ was used. The calculated latent heat flux for each track can be seen in the right panels of Fig. 11.

The $Q_{e}$ over the ocean is negative in response to SSTs that are higher than the air temperature just above the ocean surface. This corresponds to net evaporation from the ocean surface. As seen, stronger wind speeds create more negative $Q_{e}$ values, while calm winds results in flux values closer to zero. Smoothing the winds (as described above) also drastically reduced the noise in the flux retrievals. This is important because even a $1^{\circ} \mathrm{C}$ change in SST or air temperature can create (or destroy) enough instability to enable (prevent) convection. Importantly, with sufficient smoothing and/or high RCG, CYGNSS is enabling estimates of surface fluxes $\left(Q_{e}\right)$ across the heavily raining line near the gust-front boundary.

Figure 12 is similar to Fig. 8 but for a representative CYGNSS track through convection on 21 December. At 1600 UTC (before the overpass; Fig. 12a), there is a decreasing trend in WRF wind speed toward the east, but wind speed gradients are more pronounced across shallow cells near $85^{\circ}$ and $86^{\circ} \mathrm{E}$ along the track. During the overpass (1800 UTC; Fig. 12b), the easternmost cell has developed significantly, leading to a sharp increase in winds along its leading edge. The wind increase is associated with downdraft development in the mature MCS. Both the filtered and unfiltered CYGNSS winds faithfully reproduce the gust front, with once again the unfiltered winds skewing slightly closer to WRF along the sharp gradients of the gust front, though at the expense of providing a worse match elsewhere. After the overpass, by 1930 UTC (Fig. 12c) the convective system has weakened, though a gust front still exists and has broadened in overall width even as the peak wind speed has decreased. The wind speed maximum has moved eastward with the convection and is more closely aligned with the heaviest precipitation. This overall life cycle is very similar to that shown in Fig. 8, demonstrating how CYGNSS will provide useful information about convective evolution when using this track-based approach, particularly when paired with precipitation observations (e.g., radar).

\section{Conclusions}

The DYNAMO campaign made intensive observations of MJO onsets over the Indian Ocean. Dense observational data were collected during the life cycles of three MJO events that occurred October-December 2011. This study examined mesoscale tropical convection during the onset of October and December 2011 MJO events. The enhanced observational datasets, including upper-air sounding, surface observations, ASCAT/OACAT ocean surface wind, and radar data from the DYNAMO campaign, were assimilated using the WRF 3DVAR system to provide an improved initial condition for the WRF Model to create an expansive and accurate wind field to be ingested into the CYGNSS E2ES. The purpose of this study was twofold: 1) to demonstrate how satellite simulators can be used to examine a mission's capabilities for accomplishing secondary tasks (in the case of CYGNSS, characterizing tropical convection and the $\mathrm{MJO}$ ) and 2) to examine how CYGNSS surface wind observations can add value to future tropical oceanic field campaigns.

This study was centered around the ability of CYGNSS to characterize the mesoscale convective variability associated with tropical convection during the MJO. In the Indian Ocean, this convection commonly is organized into clusters that are associated with WWBs. Individual convective elements within these convective storm clusters and MCSs often produced localized increases in near-surface wind speeds associated with downdraft-induced gust fronts. Because of the assimilation of DYNAMO observations, the WRF simulations were able to produce realistic simulations of WWB-associated convection. Accurate WRF modeling 

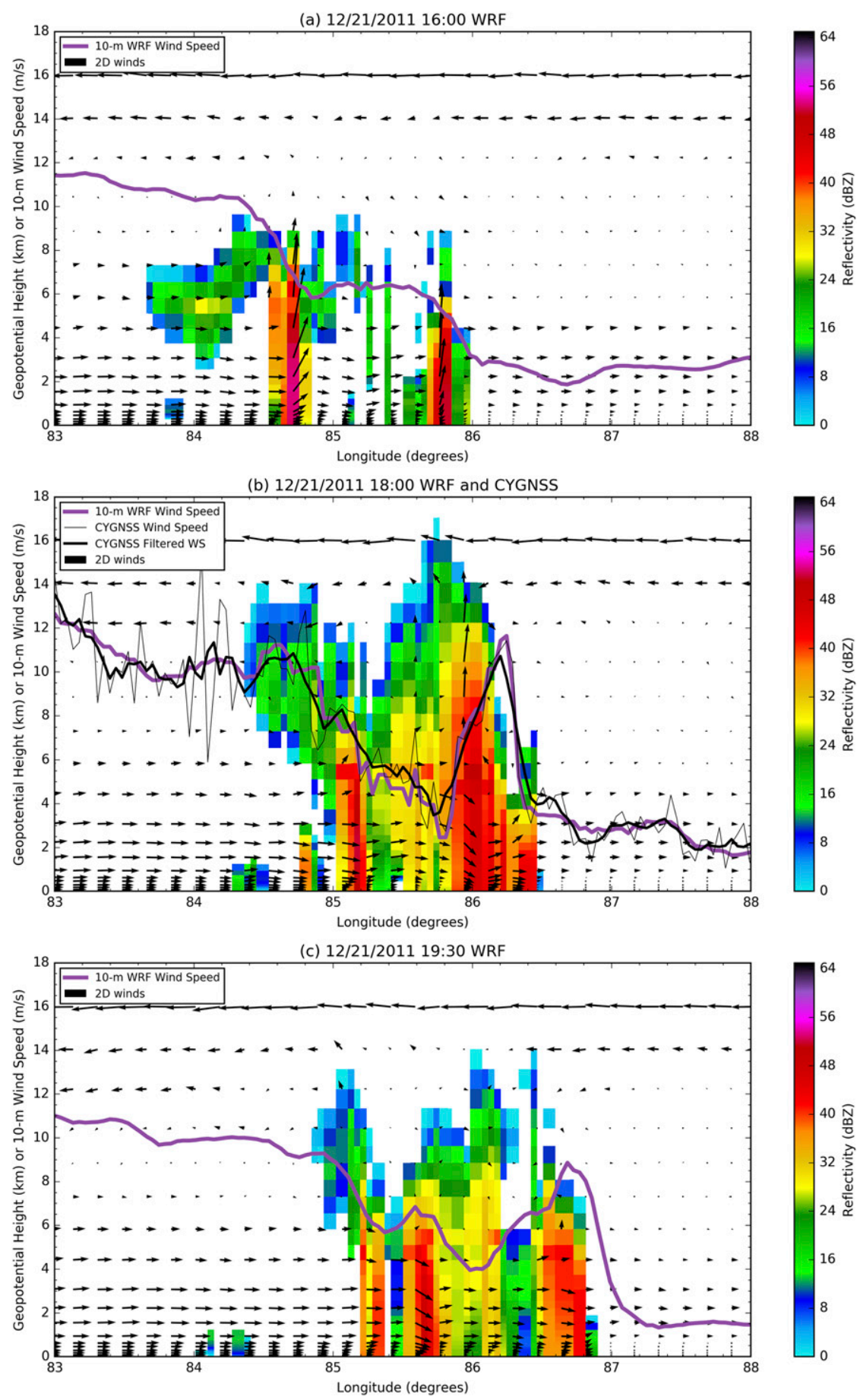

FIG. 12. Vertical cross section along a representative CYGNSS specular point track of WRF 10-cm simulated radar reflectivity (colors), 10-m WRF wind speeds (purple), and 2D winds in the plane of the track (vectors) at three specific times on 21 Dec 2011. Vectors are for qualitative purposes only; they have been thinned by a factor of 2 in the vertical and a factor of 4 in the horizontal, and the vertical component has been magnified by a factor of 10. (a) 1600 UTC. (b) 1800 UTC, corresponding to the actual CYGNSS track occurrence. CYGNSS wind speed (raw and five-point boxcar filtered) is shown as well. (c) 1930 UTC. 
of the MJO was a crucial first step before applying the E2ES, and future satellite simulator studies are encouraged to use data assimilation and other model improvements to characterize the phenomena of interest as accurately as possible.

Because the E2ES was run in fast mode, without full DDM retrievals, it is likely that the simulated CYGNSS winds are less accurate than they would be under a full simulation. This is because the instrument error model for the fast mode is parameterized, thereby introducing an additional source of uncertainty for the wind speed retrievals. This was an acceptable trade-off because it greatly improved the computational performance of the E2ES, and it constituted a "worst case" scenario for attempting to discern convective wind signals in the CYGNSS data. That is, the ability to observe convectively driven winds in heavy precipitation from the fast-mode E2ES suggests that this should be also possible with real constellation data. In addition, the E2ES was subsequently able to produce realistic tracks of CYGNSS specular points using the WRF-based input atmosphere, which then adequately demonstrated trade-offs between RCG and retrieval accuracy.

In terms of how CYGNSS may add value to future field campaigns, the results of this study suggest the following recommendations. First of all, there is natural spatial sparseness to CYGNSS data, in that successive specular point tracks do not line up in a spatially contiguous swath like traditional scatterometers. However, counteracting this data sparseness is the fact that CYGNSS will provide much more frequent revisit times at a particular location as compared to ASCAT, OSCAT and QuikSCAT. In addition, this study demonstrated that CYGNSS is capable of resolving convective wind features, such as gust fronts and WWBs, even in the presence of heavy rain. Thus, CYGNSS data are useful for process studies involving tropical convection.

An additional recommendation from this study is that it may be helpful to adopt a "track based" approach, in which other platforms' views of convection are analyzed in the context of 1D surface wind variability along a particular CYGNSS track. One example is employing range-height indicator ( $\mathrm{RHI}$ ) scans with a surface-based weather radar along known CYGNSS specular point tracks (that can be predicted in advance). Since CYGNSS overpasses are much more common given the multiple tracks simultaneously (four per satellite) being observed by multiple satellites (eight total in the constellation), the chances for overpasses occurring during convection within a field campaign's domain are much higher than with traditional scatterometers. Similar approaches can be adopted for specialized point- or column-based measurements (e.g., a sounding)—-these can be timed to coincide with a nearby CYGNSS track. Some field platforms will provide similar measurements (e.g., near-surface wind speed), which can enable a greater volume of calibration/validation data to be collected for CYGNSS. Yet, most field campaign platforms will provide complementary observations (e.g., radar reflectivity or upper-level winds), and the CYGNSS observations can be used to support case studies or statistical analyses of tropical convection in combination with multiple datasets.

Finally, with sufficient filtering and/or high RCG $\left(>10 \mathrm{~m}^{-4}\right)$, CYGNSS data may assist with improvements in air-sea flux estimates within and near convection. For low RCG $\left(<10 \mathrm{~m}^{-4}\right)$, filtering can reduce wind errors by as much as a factor of 2 . In general, aggressive filters (e.g., the forward-back method) perform better than less aggressive ones (e.g., the centered method) in these low-RCG situations. Luckily, RCG is reported in CYGNSS Level 2 winds data, so end users can apply this variable to make decisions about whether filtering is necessary. However, some care will need to be taken when interpreting filtered data near organized precipitation, particularly near suspected gust fronts, as very sharp wind gradients may be reduced in magnitude. But regardless of filtering, since flux estimates are of great interest to most oceanic field experiments, it would benefit future campaigns (e.g., PISTON) for their steering committees to consider CYGNSS as they develop observing strategies.

Acknowledgments. This research was funded by the NASA Weather program under the direction of Dr. Ramesh Kakar (NASA Grant NNM11AA01A). All DYNAMO data were provided by the National Center for Atmospheric Research Earth Observing Laboratory (NCAR EOL) under sponsorship of the National Science Foundation. These data may be obtained online (http:// data.eol.ucar.edu/master_list/?project=DYNAMO). The WRF Model code is also available online (https://www. mmm.ucar.edu/weather-research-and-forecasting-model). The CYGNSS project lead is Chris Ruf of the University of Michigan; contact him at cruf@umich.edu to request access to the CYGNSS E2ES. Contact this paper's corresponding author for access to the processing scripts and analyses performed in this study. The views, opinions, and findings in this report are those of the authors, and should not be construed as an official NASA or U.S. government position, policy, or decision. The authors wish to thank three anonymous reviewers for their help toward significantly improving this manuscript. 


\section{REFERENCES}

Abualnaja, Y., V. P. Papadopoulos, S. A. Josey, I. Hoteit, H. Kontoyiannis, and D. E. Raitsos, 2015: Impact of climate modes on air-sea heat exchange in the Red Sea. J. Climate, 28, 2665-2681, https://doi.org/10.1175/JCLI-D-14-00379.1.

Barker, D. M., W. Huang, Y.-R. Guo, A. J. Bourgeois, and Q. N. Xiao, 2004: A three-dimensional variation data assimilation system for MM5: Implementation and initial results. Mon. Wea. Rev., 132, 897-914, https://doi.org/10.1175/ 1520-0493(2004)132<0897:ATVDAS > 2.0.CO;2.

Barrett, B. S., and L. M. Leslie, 2009: Links between tropical cyclone activity and Madden-Julian oscillation phase in the North Atlantic and northeast Pacific basins. Mon. Wea. Rev., 137, 727-744, https://doi.org/10.1175/2008MWR2602.1.

de Szoeke, S. P., J. B. Edson, J. R. Marion, C. W. Fairall, and L. Bariteau, 2015: The MJO and air-sea interaction in TOGA COARE and DYNAMO. J. Climate, 28, 597-622, https:// doi.org/10.1175/JCLI-D-14-00477.1.

Emanuel, K. A., 1987: An air-sea interaction model of intraseasonal oscillations in the tropics. J. Atmos. Sci., 44, 2324-2340, https://doi.org/10.1175/1520-0469(1987)044<2324: AASIMO $>2.0 . \mathrm{CO} ; 2$

1993: The effect of convective response time on WISHE modes. J. Atmos. Sci., 50, 1763-1775, https://doi.org/10.1175/ 1520-0469(1993)050<1763:TEOCRT $>2.0 . C O ; 2$.

1994: Atmospheric Convection. Oxford University Press, $580 \mathrm{pp}$.

Foti, G., C. Gommenginger, P. Jales, M. Unwin, A. Shaw, C. Robertson, and J. Rosell, 2015: Spaceborne GNSS reflectometry for ocean winds: First results from the UK TechDemoSat-1 mission. Geophys. Res. Lett., 42, 5435-5441, https://doi.org/10.1002/2015GL064204.

Fuchs, Z., and D. J. Raymond, 2017: A simple model of intraseasonal oscillations. J. Adv. Model. Earth Syst., 9, 1195-1211, https://doi.org/10.1002/2017MS000963.

Goswami, B. N., 2012: South Asian monsoon. Intraseasonal Variability in the Atmosphere-Ocean Climate System, 2nd ed. W. K.-M. Lau and D. E. Waliser, Eds., Environmental Sciences, Springer, 21-72.

Gottschalck, J., P. E. Roundy, C. J. Schreck III, A. Vintzileos, and C. Zhang, 2013: Large-scale atmospheric and oceanic conditions during the 2011-12 DYNAMO field campaign. Mon. Wea. Rev., 94, 1849-1870, https://doi.org/10.1175/mwr-d13-00022.1.

Hendon, H. H., and B. Liebmann, 1990: The intraseasonal (30-50 day) oscillation of the Australian summer monsoon. J. Atmos. Sci., 47, 2909-2923, https://doi.org/10.1175/15200469(1990)047<2909:TIDOOT>2.0.CO;2.

—, M. C. Wheeler, and C. Zhang, 2007: Seasonal dependence of the MJO-ENSO relationship. J. Climate, 20, 531-543, https:// doi.org/10.1175/JCLI4003.1.

Kim, J.-H., C.-H. Ho, H.-S. Kim, C.-H. Sui, and S. K. Park, 2008: Systematic variation of summertime tropical cyclone activity in the western North Pacific in relation to the Madden-Julian oscillation. J. Climate, 21, 1171-1191, https://doi.org/10.1175/ 2007JCLI1493.1.

Klotzbach, P. J., 2010: On the Madden-Julian oscillation-Atlantic hurricane relationship. J. Climate, 23, 282-293, https://doi.org/ 10.1175/2009JCLI2978.1.

Knutson, R. R., K. M. Weickmann, and J. E. Kutzbach, 1986: Global-scale intraseasonal oscillations of outgoing longwave radiation and $250 \mathrm{mb}$ zonal wind during Northern Hemisphere summer. Mon. Wea. Rev., 114, 605-623, https://doi.org/ 10.1175/1520-0493(1986)114<0605:GSIOOO>2.0.CO;2.

LaFleur, D. M., B. S. Barrett, and G. R. Henderson, 2015: Some climatological aspects of the Madden-Julian oscillation (MJO). J. Climate, 28, 6039-6053, https://doi.org/10.1175/ JCLI-D-14-00744.1.

Lawrence, D. M., and P. J. Webster, 2002: The boreal summer intraseasonal oscillation: Relationship between northward and eastward movement of convection. J. Atmos. Sci., 59, 1593-1606, https://doi.org/10.1175/1520-0469(2002)059<1593: TBSIOR $>2.0 . \mathrm{CO} ; 2$

$\mathrm{Li}, \mathrm{X}$., and Z. Pu, 2008: Sensitivity of numerical simulation of early rapid intensification of Hurricane Emily (2005) to cloud microphysical and planetary boundary layer parameterizations. Mon. Wea. Rev., 136, 4819-4838, https://doi.org/10.1175/ 2008MWR2366.1.

Ling, J., P. Bauer, P. Bechtold, A. Beljaars, R. Forbes, R. Vitart, M. Ulate, and C. Zhang, 2014: Global versus local MJO forecast skill of the ECMWF model during DYNAMO. Mon. Wea. Rev., 142, 2228-2247, https://doi.org/10.1175/ MWR-D-13-00292.1.

Madden, R. A., and P. R. Julian, 1971: Detection of a 40-50 day oscillation in the zonal wind in the tropical Pacific. J. Atmos. Sci., 28, 702-708, https://doi.org/10.1175/ 1520-0469(1971)028<0702:DOADOI >2.0.CO;2.

$\longrightarrow$, and - 1972: Description of global-scale circulation cells in the Tropics with a 40-50 day period. J. Atmos. Sci., 29, 1109-1123, https://doi.org/10.1175/1520-0469(1972)029<1109 DOGSCC $>2.0 . C O ; 2$.

Markowski, P., and Y. Richardson, 2010: Mesoscale Meteorology in Midlatitudes. John Wiley \& Sons, 407 pp., https://doi.org/ 10.1002/9780470682104.

Mo, K. C., C. Jones, and J. Nogués Paegle, 2012: Pan America. Intraseasonal Variability in the Atmosphere-Ocean Climate System, 2nd ed. W. K.-M. Lau and D. E. Waliser, Eds., Environmental Sciences, Springer, 111-145.

Moum, J. N., and Coauthors, 2014: Air-sea interactions from westerly wind bursts during the November 2011 MJO in the Indian Ocean. Bull. Amer. Meteor. Soc., 95, 1185-1199, https:// doi.org/10.1175/BAMS-D-12-00225.1.

Neelin, J. D., I. M. Held, and K. H. Cook, 1987: Evaporation-wind feedback and low-frequency variability in the tropical atmosphere. J. Atmos. Sci., 44, 2341-2348, https://doi.org/10.1175/ 1520-0469(1987)044<2341:EWFALF $>2.0 . C O ; 2$.

O'Brien, A., 2014: End-to-end simulator technical memo. Space Physics Research Laboratory Doc. 148-0123, University of Michigan, 24 pp., http://clasp-research.engin.umich.edu/ missions/cygnss/reference/148-0123_CYGNSS_E2ES_EM.pdf.

— S. Gleason, J. Johnson, and C. Ruf, 2015: The CYGNSS endto-end simulator (E2ES). GNSS+R 2015 Workshop, Potsdam, Germany, GFZ, S5T03, ftp://ftp.gfz-potsdam.de/pub/GNSS/ workshops/gnssr2015/session5/S5T03_OBrien_-_The_CYGNSS_ end-to-end_simulator.pdf.

Parrish, D. F., and J. C. Derber, 1992: The National Meteorological Center's spectral statistical-interpolation analysis system. Mon. Wea. Rev., 120, 1747-1763, https://doi.org/10.1175/ 1520-0493(1992)120<1747:TNMCSS $>2.0$. CO;2.

Powell, S. W., and R. A. Houze Jr., 2013: The cloud population and onset of the Madden-Julian oscillation over the Indian ocean during DYNAMO-AMIE. J. Geophys. Res. Atmos., 118, 11 979-11 995, https://doi.org/10.1002/2013jd020421.

Riley-Dellaripa, E. M., E. D. Maloney, and S. van den Heever, 2016: Diagnosing moistening processes of the November 
DYNAMO MJO by cloud resolving model simulations. 32nd Conf. on Hurricanes and Tropical Meteorology, San Juan, Puerto Rico, Amer. Meteor. Soc., 17B.9, https://ams.confex.com/ ams/32Hurr/webprogram/Paper293550.html.

Rowe, A. K., and R. A. Houze Jr., 2014: Microphysical characteristics of MJO convection over the Indian Ocean during DYNAMO. J. Geophys. Res. Atmos., 119, 2543-2554, https:// doi.org/10.1002/2013jd020799.

Ruf, C., A. Lyons, M. Unwin, J. Dickinson, R. Rose, D. Rose, and M. Vincent, 2013a: CYGNSS: Enabling the future of hurricane prediction. IEEE Geosci. Remote Sens. Mag., 52-67, https://doi.org/10.1109/mgrs.2013.2260911.

,-- , and A. Ward, 2013b: NASA intensifies hurricane studies with CYGNSS. The Earth Observer, Vol. 25, No. 3, Earth Observing System Project Science Office, Greenbelt, MD, 12-21.

— probe hurricanes and tropical convection. Bull. Amer. Meteor. Soc., 97, 385-395, https://doi.org/10.1175/BAMS-D-14-00218.1.

Skamarock, W. C., and Coauthors, 2008: A description of the Advanced Research WRF version 3. NCAR Tech. Note NCAR/TN-475+STR, 113 pp., http://dx.doi.org/10.5065/ D68S4MVH.

Skyllingstad, E. D., and S. P. de Szoeke, 2015: Cloud-resolving large-eddy simulation of tropical convective development and surface fluxes. Mon. Wea. Rev., 143, 2441-2458, https://doi.org/ 10.1175/MWR-D-14-00247.1.

Sobel, A. H., and E. D. Maloney, 2013: Moisture modes and the eastward propagation of the MJO. J. Atmos. Sci., 70, 187-192, https://doi.org/10.1175/JAS-D-12-0189.1.

,-- , G. Bellon, and D. M. Frierson, 2010: Surface fluxes and tropical intraseasonal variability: A reassessment. $J$. Adv. Model. Earth Syst., 2 (2), https://doi.org/10.3894/JAMES.2010.2.2.

Solodoch, A., W. R. Boss, Z. Kuang, and E. Tziperman, 2011: Excitation of intraseasonal variability in the equatorial atmosphere by Yanai wave groups via WISHE-induced convection. J. Atmos. Sci., 68, 210-225, https://doi.org/10.1175/ 2010JAS3564.1.

Weickmann, K. M., G. R. Lussky, and J. E. Kutzbach, 1985: Intraseasonal (30-60 day) fluctuations of outgoing longwave radiation and the 250-mb streamfunction during northern winter. Mon. Wea. Rev., 113, 941-961, https://doi.org/10.1175/ 1520-0493(1985)113<0941:IDFOOL>2.0.CO;2.
Wheeler, M. C., and H. H. Hendon, 2004: An all-season real-time multivariate MJO index: Development of an index for monitoring and prediction. Mon. Wea. Rev., 132, 1917-1932, https://doi.org/ 10.1175/1520-0493(2004)132<1917:AARMMI>2.0.CO;2.

- and J. L. McBride, 2012: Australasian monsoon. Intraseasonal Variability in the Atmosphere-Ocean Climate System, 2nd ed. W. K.-M. Lau and D. E. Waliser, Eds., Environmental Sciences, Springer, 147-197.

Woolnough, S. J., J. M. Slingo, and B. J. Hoskins, 2000: The relationship between convection and sea surface temperature on intraseasonal timescales. J. Climate, 13, 2086-2104, https://doi. org/10.1175/1520-0442(2000)013<2086:TRBCAS>2.0.CO;2.

Xiao, Q., Y.-H. Kuo, J. Sun, W.-C. Lee, E. Lim, Y.-R. Guo, and D. M. Barker, 2005: Assimilation of Doppler radar observations with a regional 3DVAR system: Impact of Doppler velocities on forecasts of a heavy rainfall case. J. Appl. Meteor., 44, 768-788, https://doi.org/10.1175/JAM2248.1.

,,$---\longrightarrow$, D. M. Barker, and E. Lim, 2007: An approach of radar reflectivity data assimilation and its assessment with the inland QPF of Typhoon Rusa (2002) at landfall. J. Appl. Meteor. Climatol., 46, 14-22, https://doi.org/10.1175/ JAM2439.1.

$\mathrm{Xu}, \mathrm{W}$., and S. A. Rutledge, 2015: Morphology, intensity, and rainfall production of MJO convection: Observations from DYNAMO and TRMM. J. Atmos. Sci., 72, 623-640, https:// doi.org/10.1175/JAS-D-14-0130.1.

Yoneyama, K., C. Zhang, and C. N. Long, 2013: Tracking pulses of the Madden-Julian oscillation. Bull. Amer. Meteor. Soc., 94, 1871-1891, https://doi.org/10.1175/BAMS-D-12-00157.1.

Zhang, C., 2005: Madden-Julian Oscillation. Rev. Geophys., 43, RG2003, https://doi.org/10.1029/2004rg000158.

_ 2013: Madden-Julian oscillation: Bridging weather and climate. Bull. Amer. Meteor. Soc., 94, 1849-1870, https://doi.org/ 10.1175/BAMS-D-12-00026.1.

, J. Gottschalck, E. D. Maloney, M. W. Moncrieff, F. Vitart, D. E. Waliser, B. Wang, and M. C. Wheeler, 2013: Cracking the MJO nut. Geophys. Res. Lett., 40, 1223-1230, https:// doi.org/10.1002/grl.50244.

Zuluaga, M. D., and R. A. Houze, 2013: Evolution of the population of precipitating convective systems over the equatorial Indian Ocean in active phases of the Madden-Julian oscillation. J. Atmos. Sci., 70, 2713-2725, https://doi.org/10.1175/ JAS-D-12-0311.1. 